\title{
Ontogeny and polarization of macrophages in inflammation: blood monocytes versus tissue macrophages
}

\author{
Adwitia Dey ${ }^{1,2 \dagger}$, Joselyn Allen ${ }^{1,3 \dagger}$ and Pamela A. Hankey-Giblin ${ }^{1,2,3 *}$ \\ 1 Department of Veterinary and Biomedical Sciences, The Pennsylvania State University, University Park, PA, USA \\ ${ }^{2}$ Graduate Program in Physiology, The Pennsylvania State University, University Park, PA, USA \\ ${ }^{3}$ Graduate Program in Immunology and Infectious Disease, The Pennsylvania State University, University Park, PA, USA
}

\section{Edited by: \\ Charles Dudley Mills, BioMedical Consultants, USA}

\section{Reviewed by:}

Wolfgang J. Streit, University of Florida, USA

Masaaki Murakami, Hokkaido

University, Japan

\section{*Correspondence:}

Pamela A. Hankey-Giblin, 115 Henning

Building, University Park, PA 16802,

USA

e-mail:phc7@psu.edu

${ }^{\dagger}$ Co-first authors
The explosion of new information in recent years on the origin of macrophages in the steady-state and in the context of inflammation has opened up numerous new avenues of investigation and possibilities for therapeutic intervention. In contrast to the classical model of macrophage development, it is clear that tissue-resident macrophages can develop from yolk sac-derived erythro-myeloid progenitors, fetal liver progenitors, and bone marrow-derived monocytes. Under both homeostatic conditions and in response to pathophysiological insult, the contribution of these distinct sources of macrophages varies significantly between tissues. Furthermore, while all of these populations of macrophages appear to be capable of adopting the polarized M1/M2 phenotypes, their respective contribution to inflammation, resolution of inflammation, and tissue repair remains poorly understood and is likely to be tissue- and disease-dependent. A better understanding of the ontology and polarization capacity of macrophages in homeostasis and disease will be essential for the development of novel therapies that target the inherent plasticity of macrophages in the treatment of acute and chronic inflammatory disease.

Keywords: tissue-resident macrophages, M1M2, microglia, adipose tissue macrophages, Kupffer cells, obesity, neurodegenerative disease, hepatic steatosis
Macrophages are a heterogeneous population of immune cells that have a range of roles in both the induction and resolution of inflammation. Tissue-resident macrophages promote tissue homeostasis and exhibit unique transcriptional profiles and characteristics depending on the tissue in which they reside (1). For instance, alveolar macrophages regulate pulmonary surfactant turnover while osteoclasts promote bone resorption, and red-pulp macrophages (RPMs) in the spleen promote red blood cell clearance and regulate iron recycling. In addition, multiple macrophage subtypes occur within a given tissue, and they can perform distinct functions depending on their anatomical location (2). For example, in the bone there are at least two types of tissue macrophages. $\mathrm{TRAP}^{+} \mathrm{F} 4 / 80^{-}$osteoclasts promote bone resorption while $\mathrm{F} 4 / 80^{+} \mathrm{CD} 69^{+} \mathrm{TRAP}^{-}$tissue-resident macrophages promote red blood cell development by providing a niche that promotes erythropoiesis and engulfing the extruded nuclei of red blood cell (RBC) progenitors at late stages of development (Figure 1A). Depletion of $\mathrm{CD}_{169^{+}}$macrophages results in impaired recovery of mice from hemolytic anemia (3). Recent studies suggest these two macrophage populations in the bone are replenished by distinct subsets of monocytes in response to stress. $\mathrm{Mac}^{+} \mathrm{F} 4 / 80^{-}$monocytes regulate osteoclast activity but are not thought to be precursors of osteoclasts under homeostatic conditions (Figure 1A). However, these cells can differentiate into osteoclasts under inflammatory conditions. Alternatively, in the presence of increased levels of extracellular heme resulting from conditions of stress such as hemolytic anemia, a subpopulation of monocytes in the bone marrow and spleen develop into $\mathrm{F} 4 / 80^{+} \mathrm{CD} 11 \mathrm{~b}^{\text {hi }}$ progenitors termed pre-RPMs and subsequently into RPMs and $\mathrm{F} 4 / 80^{+} \mathrm{VCAM}^{+}$bone marrow macrophages that resemble RPMs to re-establish iron homeostasis (Figure 1A) (4).

In the developing embryo, hematopoiesis begins in the yolk sac where primitive erythrocytes and macrophages develop in the absence of hematopoietic stem cells (HSCs). Subsequently, HSCs arise in the aorto-gonado-mesonephric (AGM) region and eventually migrate to the fetal liver where development of all hematopoietic lineages from HSCs occurs. In the neonate, hematopoiesis moves from the fetal liver to the bone marrow where it persists throughout adulthood. The traditional view of macrophage origin contended that tissue-resident macrophages develop from bone marrow-derived monocytes. It was subsequently believed that tissue-resident macrophages derive from Ly6C - "resident" monocytes that traffic to tissues under homeostatic conditions. However, studies utilizing Runx1 ${ }^{\text {CreER }}$ and Csf1 ${ }^{\text {CreER }}$ mice, which allow for tamoxifen-inducible activation of Cre during the early stages of yolk sac hematopoiesis crossed with $\operatorname{Rosa}^{26}$ mice to label yolk sac-derived (YS) cells (5) have indicated that some tissue macrophages arise from the yolk sac and seed tissues in the embryo where they repopulate throughout adulthood $(6,7)$. Studies utilizing Flt3 ${ }^{\text {Cre }}$ mice to mark HSC-derived macrophages confirm that YS tissue macrophages $\left(\mathrm{Flt} 3^{\mathrm{Cre}-}\right)$ are distinct from HSC-derived macrophages $\left(\mathrm{Flt} 3^{\mathrm{Cre}+}\right)$ 

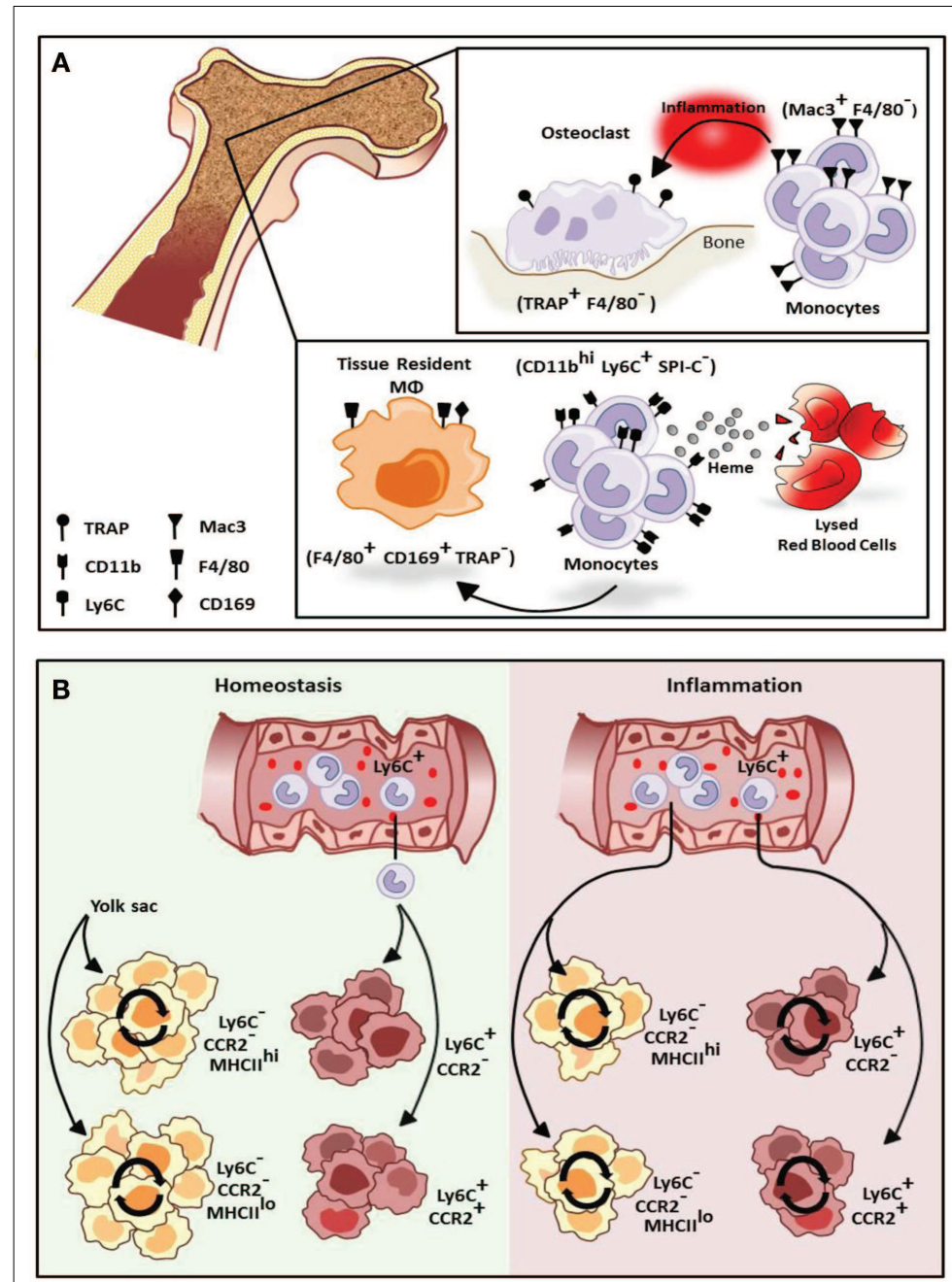

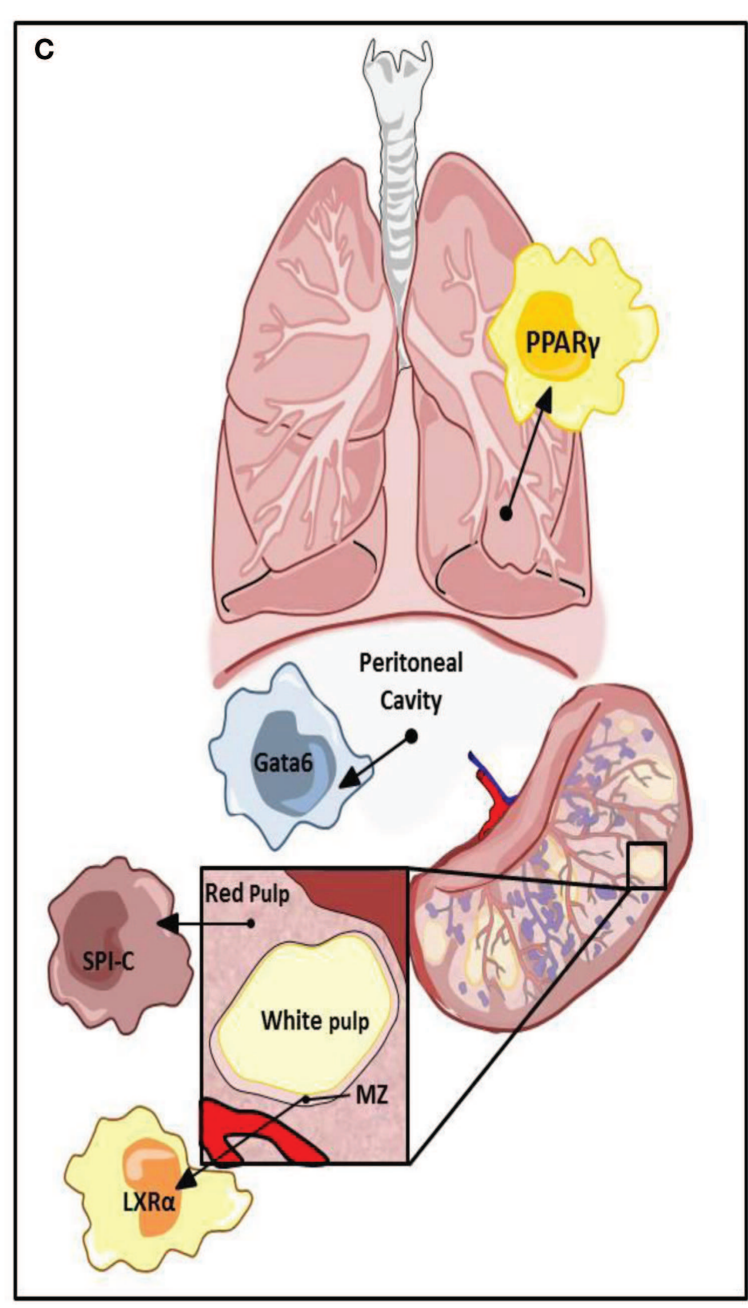

FIGURE 1 | Differentiation of resident macrophages in various physiological states. (A) Two tissue macrophage populations reside in bone, F4/80- TRAP $^{+}$osteoclasts and F4/80 ${ }^{+} \mathrm{CD}_{169}{ }^{+} \mathrm{TRAP}^{-}$

tissue-resident macrophages (MФs). Osteoclasts are developmentally dependent on $\mathrm{Mac}^{+} \mathrm{F} 4 / 80^{-}$monocytes but only during inflammation. Alternatively, tissue-resident macrophages in bone can be maintained by a heme-induced subset of monocytes (CD11 bi ${\text { Ly } 6 C^{+} \text {SPI-C }}^{-}$). (B) Cardiac tissue-resident macrophage populations are primarily yolk sac-derived (YS) however a minor subset of the population is derived from fetal liver and HSC-derived progenitors. In homeostasis, primary yolk sac-derived cardiac resident macrophages are maintained through self-renewal but in response to cardiac insult, Ly6 $\mathrm{C}^{\text {hi }}$ monocytes contribute to all four macrophage populations. (C) Selective transcriptional control plays an important role in the development of different types of macrophage populations. While red-pulp macrophages are dependent on SPI-C activity for development and maintenance, marginal zone (MZ) macrophage differentiation is mediated by $L X R \alpha$. Alternatively, Gata6 is mandatory for the differentiation and proliferation of peritoneal macrophages while GM-CSF-dependent induction of PPAR $\gamma$ regulate alveolar macrophage development. thus challenging the traditional view of macrophage ontogeny. Kupffer cells, microglia, and cardiac tissue macrophages are primarily YS and are maintained throughout adulthood. These cells are independent of the transcription factor $\mathrm{Myb}$, which is required for the development of HSCs, suggesting these populations of tissue-resident macrophages develop and persist independent of contribution from HSCs (8).

While Langerhans cells are first seeded by yolk sac macrophages, these cells are largely replaced by fetal liver-derived monocytes at later stages of embryonic development as demonstrated by adoptive transfer of fetal liver monocytes to host embryos (9). In addition, studies utilizing the $\mathrm{CX}_{3} \mathrm{C}$ chemokine receptor $1\left(\mathrm{CX}_{3} \mathrm{CR} 1\right)$ promoter, which marks fetal-derived resident macrophage populations to drive GFP, Cre or a tomoxifeninducible Cre together with adoptive transfer studies have demonstrated that peritoneal macrophages and alveolar macrophages are also largely fetal liver-derived. While cardiac tissue macrophages are also largely YS, two minor populations also display contribution from fetal liver and bone marrow progenitors (10-12). Other tissue-resident macrophages including those from spleen, pancreas, and kidney also exhibit mixed contribution from fetal and adult HSC-derived precursors (13), while intestinal macrophages appear to be entirely derived from circulating monocytes $(14,15)$. While these studies make a distinction between YS and fetal liverderived macrophages, a recent report describes an erythro-myeloid progenitor (EMP) population that develops in the yolk sac and 
later migrates to the liver. These progenitors are distinct from HSC-derived hematopoiesis, suggesting that YS and fetal liverderived tissue-resident macrophages have a common origin in the yolk sac (16).

Unlike previous assumptions that macrophages are terminally differentiated cells, YS macrophages appear to have stem celllike properties in that they can proliferate and self-renew (9). In the lung, tissue-resident macrophages are maintained locally in the steady state. Moreover, following irradiation and bone marrow transplantation, residual lung-resident macrophages can re-establish normal homeostasis when the development of donorderived macrophages is compromised (13). These cells expand in response to colony-stimulating factors, M-CSF and GM-CSF, in an interleukin 4 (IL-4)-independent manner. It is therefore likely that, following irradiation, the expansion of resident macrophages is delayed giving the monocyte-derived macrophages a developmental advantage. Alternatively, in response to helminth infection, Th2-dependent production of IL-4 promotes the proliferation of lung-resident macrophages (17) and this proliferation is independent of colony-stimulating factor-1 (CSF-1) (18). However, while Langerhans cells are embryonic-derived cells that exhibit hallmarks of self-maintenance, these cells are eventually replaced by circulating precursors following nonmyeloablative transplantation (19). Similarly, YS cardiac resident macrophages are maintained through local proliferation, while monocyte-derived cells can replace all populations of resident cardiac macrophages following depletion or in response to damage (Figure 1B) (10, 20).

The development and maintenance of tissue-resident macrophages is also under tissue-selective transcriptional control. The transcription factor Gata6 is responsible for the transcriptome profile of resident peritoneal macrophages as well as for their proliferation under homeostatic conditions and in response to inflammation (Figure 1C) (21) and this programing is regulated reversibly by retinoic acid-induced Gata6 expression (22). Reflecting the fetal origin of peritoneal macrophages, retinoic acid induces expression of Gata6 in fetal-derived macrophages but not bone marrow-derived macrophages (BMDMs) due to epigenetic silencing of the Gata6 locus in BMDMs (22). Alternatively, the development of alveolar macrophages from fetal monocytes shortly after birth is regulated by the GM-CSFdependent induction of peroxisome proliferator-activated receptor $\gamma(\operatorname{PPAR} \gamma)$, resulting in a transcriptosome profile unique to alveolar macrophages (Figure 1C) (23). The development of splenic RPMs in response to excess heme requires the transcription factor SPI-C (Figure 1C) (4), however, marginal zone (MZ) macrophages develop normally in SPI-C knockout animals. MZ macrophages play a critical role in the recognition and uptake of blood-borne antigens. While the differentiation of RPMs requires SPI-C, the differentiation of both populations of $\mathrm{MZ}$ macrophages is under the regulatory control of the nuclear receptor, liver $\mathrm{x}$ receptor $\alpha(\mathrm{LXR} \alpha)$ (Figure 1C) (24), and $\mathrm{LXR} \alpha$-deficient mice exhibit abnormal responses to blood-borne antigens.

Unlike previous assumptions that $\mathrm{Ly} 6 \mathrm{C}^{-}$monocytes are precursors of tissue-resident macrophages, it has recently been shown that these monocytes do not infiltrate tissues but rather have a "patrolling" function in promoting endothelial integrity. Alternatively, $\mathrm{Ly}^{+} \mathrm{C}^{+}$"inflammatory" monocytes are actively recruited to inflamed tissues by the chemokine, chemokine ligand 2 (CCL2) where they promote inflammation and pathogen clearance. Analogous populations of monocytes in humans have been described based on gene expression analysis and are classified as $\mathrm{CD} 14^{\mathrm{hi}} \mathrm{CD} 16^{-}$, which are the primary subset in healthy individuals and resemble $\mathrm{Ly}_{6} \mathrm{C}^{+}$murine monocytes while the minor $\mathrm{CD} 14^{\mathrm{lo}} \mathrm{CD} 16^{+}$population of human monocytes shares gene expression profiles with murine $\mathrm{Ly}^{-} \mathrm{C}^{-}$monocytes (25). Furthermore, the $\mathrm{CD} 14^{\mathrm{lo}} \mathrm{CD} 16^{+}$population of human monocytes, like $\mathrm{Ly} 6 \mathrm{C}^{-}$monocytes, also play a role in patrolling the endothelium (26). Ly6C $\mathrm{C}^{-}$monocytes derive in the circulation from the Ly $6 \mathrm{C}^{+}$population and exhibit an extended half-life compared with Ly6C $\mathrm{C}^{+}$monocytes (9). Intriguingly, recent studies indicate that a subset of $\mathrm{Ly} 6 \mathrm{C}^{+}$monocytes can traffic to tissues under homeostatic conditions where they fail to differentiate into tissueresident macrophages, rather they acquire antigen, which they carry to the draining lymph nodes (27).

Under non-inflammatory conditions, tissue-resident macrophages largely exhibit an M2 phenotype that promotes tissue homeostasis and repair. However, upon infection, M1 macrophage activation is induced by the engagement of pattern recognition receptors (PPRs) by pathogen-associated molecular patterns (PAMPs) such as lipopolysaccharide (LPS), in cooperation with interferon $\gamma$ (IFN $\gamma)$ (28). These cells produce cytotoxic oxygen and nitrogen radicals and pro-inflammatory cytokines resulting in increased microbicidal activity. M2 macrophage activation is induced by the Th2 chemokines IL- 4 and interleukin-13 (IL-13) $(29,30)$. Alternatively, during the resolution of inflammation, the balance of macrophage activation toward an M2 phenotype occurs in order to promote clearance of debris, inhibit the production of inflammatory mediators, and restore tissue homeostasis. M2 macrophages produce anti-inflammatory cytokines and express endocytic receptors, and these cells promote the clearance of apoptotic cells, proliferation, and wound healing (28). However, the relative contribution and level of plasticity of tissue-resident versus monocyte-derived macrophage populations is only recently beginning to be elucidated.

The M1/M2 macrophage subsets are most commonly distinguished based on the catabolism of $\mathrm{L}$-arginine. While classically activated macrophages express increased levels of inducible nitric oxide synthase (iNOS), which converts L-arginine to Lcitrulline and nitric oxide, alternatively activated macrophages express arginase I (ArgI), which catabolizes $\mathrm{L}$-arginine to $\mathrm{L}$ ornithine, a precursor of polyamines and proline. While Th1 and Th2 cytokines promote M1 and M2 macrophage activation, respectively, these phenotypes are observed in T cell deficient mice suggesting that $\mathrm{T}$ helper cells are not required to drive macrophage polarization in vivo $(29,30)$. Conversely, M1 and M2 macrophages are capable of promoting Th1 and Th2 differentiation, respectively, suggesting these polarized macrophage phenotypes play an important role in driving the immune response to environmental insult (29). Recent attempts have been made to re-classify macrophage subpopulations in response to a range of stimuli and increasingly complex combination of markers (31). However, in vivo, macrophages are exposed simultaneously to a diverse array of 
signals, so it remains to be determined to what extent distinct subpopulations exist in vivo.

The origin and plasticity of macrophages in chronic inflammation remains poorly understood and is likely variable depending on the tissue and the underlying cause of inflammation. Tissueresident macrophages as well as monocyte-derived macrophages appear to have the capability of adopting both M1 and M2 phenotypes, however, the relative contribution of these subsets of macrophages to the progression and resolution of chronic inflammation remains enigmatic. Here, we will review current progress in understanding the complex relationships between tissue-resident macrophages and infiltrating monocyte-derived macrophages in homeostasis and chronic inflammation and their contributions to M1/M2 polarized phenotypes in homeostasis and disease with a focus on chronic inflammation in the brain, adipose tissue, and liver.

\section{MICROGLIA: RESIDENT CNS MACROPHAGES}

Microglia, parenchymal tissue-resident macrophages in the central nervous system, plays a central role in mediating tissue homeostasis in health and disease (32). Fate mapping studies conducted independently by Ginhoux et al. and Prinz et al. demonstrated the embryonic origin of microglia from c-kit ${ }^{+}$EMP prior to the formation of blood-brain barrier and vascularization of the embryo $(7,33,34)$. The colony-stimulating-factor 1 receptor $(\mathrm{CSF} 1 \mathrm{R})$ and its ligand, CSF-1, play a central role in macrophage development and maintenance. However, while CSF1R is essential for the development and maintenance of microglia, mice deficient for CSF-1 exhibit only a partial reduction in microglial cells. Recent studies have identified an additional ligand for CSF1R, interleukin-34 (IL-34), which plays an essential role in the development and maintenance of microglia. While mice deficient for IL-34 exhibit significantly decreased numbers of microglia and Langerhans cells, the development of other tissue macrophage populations remain largely intact $(35,36)$. After birth, the microglia undergo massive expansion in response to CSF-1 and IL-34 in order to populate the developing nervous system. Cortical, optical, and spinal cord microgliogenesis is sustained by the transcription factors $\mathrm{Pu} .1$ and interferon regulatory factor-8 (IRF-8), and is independent of Myb, which is required for the development of hematopoietic stem cells $(34,37)$. Microglia are sustained and self-renew within host tissues throughout adulthood independent of progenitors from the bone marrow (38).

In a healthy brain, microglia are dispersed relatively uniformly throughout the parenchymal tissue. Microglia are characterized by morphological features that reflect their functional capacity. In a healthy brain, microglia are in a quiescent state or have a "down-regulated" phenotype exhibited by a ramified shape, similar to Langerhans cells that have short fine processes and thus increased surface area for tissue surveillance (39). This downregulated phenotype is characterized by an attenuated innate immune function correlated with decreased expression of CD45, MHCII, and Fc receptors (39-41). Initially, it was believed that steady-state microglia are static, however, recent studies have characterized the quiescent phenotype as a more dynamic state in which microglia are performing housekeeping functions by constitutively surveying the parenchymal tissue (42). This dynamic state is characterized by increased expression of oxidative genes and favors homeostatic tissue remodeling and steady-state wound healing (43).

Recent studies by Butofsky et al. (44) demonstrate that resident microglia exhibit a distinct expression profile that is not observed in microglial cell lines and is distinct from M1 or M2 polarized microglia, but rather includes genes associated with nervous system development. The induction of this unique profile is highly dependent on transforming growth factor $\beta$ (TGF$\beta)$ - in vitro in human microglial cultures, and these cells are absent in TGF- $\beta$ knockout mice. The down-regulated phenotype of microglia is critical for normal neuronal growth, and intimate interactions between neurons and microglia are important for optimal synaptic growth and maintenance (Figure 2) (45). The interaction between neurons and microglia is fostered by the chemokine $\mathrm{CX}_{3} \mathrm{C}$ chemokine ligand $1\left(\mathrm{CX}_{3} \mathrm{CL} 1\right.$; also known as fractalkine) and CD200 membrane proteins expressed on healthy neurons that interact with their respective transmembrane protein receptors on microglia, $\mathrm{CX}_{3} \mathrm{CR} 1$, and CD200R, respectively $(32,46-48)$. These microglial receptors carry immunoreceptor tyrosine-based inhibitory motifs (ITIMs) such that, upon ligand-receptor interaction, the ITIM based receptors suppress downstream immune signaling through the recruitment of Src homology 2 domain-containing phosphatase 1 (SHP-1) (32, 4850). These cell-cell mediated interactions act synergistically with constitutively released neurotropic elements in order to create an environment fostering the down-regulated phenotype of microglia.

Whether or not bone marrow-derived cells can contribute to the microglial population remains under debate (reviewed in Prinz et al.). Bone marrow transplantation of irradiated recipient mice demonstrated that macrophages in the perivascular space and choroid plexus can be repopulated by donor cells $(51,52)$. While microglia are largely radio-resistant cells, upon irradiation and bone marrow transplantation, bone marrow-derived progenitor cells that are distinct from monocytes have been shown to seed the brain and differentiate into microglial-like macrophage cells (45). However, it is not clear whether BMDMs maintain the range of functions exhibited by YS microglia. In addition, irradiation results in the breakdown of the blood-brain barrier, thus whether the seeding of the brain with peripheral bone marrow-derived cells can occur under steady-state conditions in the presence of an intact blood-brain barrier is not known.

Like macrophages in the periphery, in vitro studies demonstrate that M1 and M2 activation can be induced in microglia by LPS and IL-4, respectively $(40,53)$. However, whether this phenotypic switching of resident microglia occurs in vivo remains unclear. Experimental models of Alzheimer's disease (AD), aging, and multiple sclerosis (MS) $(54,55)$ have demonstrated microglial heterogeneity analogous to systemic tissue-resident populations. These studies suggest that early in disease progression, microglial cells develop an altered inducible "activated" state that is functionally different from steady-state microglia. This activated state is then further subdivided into a classical M1 and alternative M2 state $(32,40)$. Morphologically, activated microglia exhibit an amoeboid shape in contrast to the quiescent ramified shape of steady-state microglia (42). While the quiescent state of microglia 


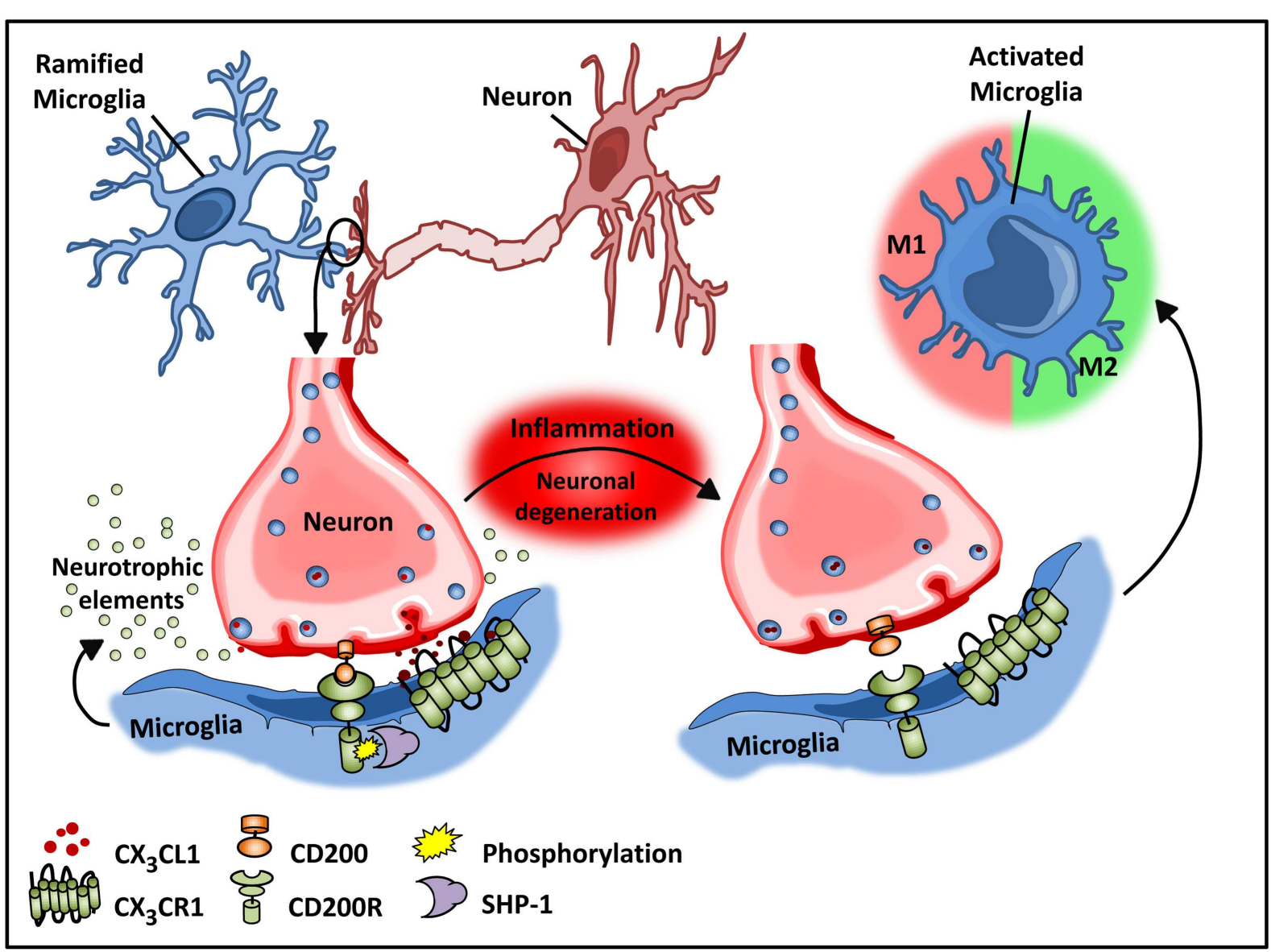

FIGURE 2 | Microglial-neuronal interactions in health and disease. Healthy neurons expressing chemokine fractalkine $\left(C X_{3} C L 1\right)$ and $C D 200$ membrane proteins intimately interact with their respective transmembrane protein receptors on microglia, $\mathrm{CX}_{3} \mathrm{CR} 1$, and CD200R to sustain a down-regulated microglial phenotype. Microglial receptors have immunoreceptor tyrosine-based inhibitory motifs (ITIMs), which upon ligand-receptor activation suppresses downstream immune signaling through the recruitment of phosphatases including SHP-1. Chronic inflammation disrupts this intimate neuronal-glial interaction, thus releasing the microglial cells from a down-regulated inhibited state to an activated phenotype. is maintained by neuronal-glial interactions, in the course of inflammation, neuronal, and glial interactions are disrupted due to degeneration of neurons $(43,56)$. Disruption of $\mathrm{CX}_{3} \mathrm{CL} 1-$ $\mathrm{CX}_{3} \mathrm{CR} 1$ interactions releases microglia from tonic inhibition (48), resulting in microglial activation as a consequence (Figure 2). Additionally, a unique "primed" microglial state, which exhibits a functional state somewhat distinct from the activated states, has been described (57). These microglia are thought to function as more of an adaptive response (57). This primed state refers to a mode of preconditioning underlying chronic inflammation whereby microglial cells are activated continuously by being persistently exposed to a pro-inflammatory milieu $(32,57)$. Importantly this priming state enables the conditioned microglia to mount a heightened response to secondary or future immunological insult in the course of disease progression. Primed microglia exhibit a more robust inflammatory response as compared to those that were not subjected to prior stimulatory challenges $(32,57)$. Additionally, the heightened inflammatory response to a physiological challenge is believed to promote a switch from a more anti-inflammatory to a pro-inflammatory reactive phenotype resulting in cellular stress and exacerbated inflammation (57).

Investigations in spinal cord injury (SCI), $\mathrm{AD}$, and the animal model of MS, also known as experimental autoimmune encephalitis (EAE) demonstrate an increase in both M1 and M2 phenotypes, possibly acting synergistically in an attempt to mitigate inflammation (40). While both M1 and M2 transcripts increase in a majority of chronic CNS disease models, the M1 phenotype offsets the M2 phenotype in the early stages of chronic inflammation, disrupting normal neuronal/glial cross-talk, and promoting a proinflammatory milieu implicated in the progression of disease (39, $40,53)$. With progressive degeneration, the M1 phenotype predominates, as M2 microglia exhibit decreased responsiveness to anti-inflammatory cues (53). Alternatively, the classically activated M1 phenotype is predominately induced by acute pathological conditions such as stroke, traumatic brain injury, or experimentally induced systemic inflammation by LPS (42). The M1 state in chronic and acute manifestations is characterized by the up-regulation of MHCII, CD86, and Fc receptors and increased 
production of pro-inflammatory cytokines such as interleukin6 (IL-6), interleukin-1 (IL-1), and tumor necrosis factor alpha $(\mathrm{TNF} \alpha)(58)$. Furthermore aging models hint at a possibility of phenotypic switch in microglial activation from an M2 to M1 state over time, coincident with decreasing neurogenesis and a growing inflammatory niche (32). However, it still remains unclear whether these populations of macrophages are due to phenotypic switching of resident microglia, or the activation states of infiltrating monocyte-derived macrophages. Interestingly, research in microglial senescence sheds light into the notion that microglial degradation precedes neurodegeneration and perhaps neurodegeneration is a secondary factor to aging induced dysregulation of microglial populations $(59,60)$.

Several studies of chronic inflammation in the CNS have demonstrated a degree of immune infiltration into the CNS, which is presumed to promote tissue remodeling as an attempt to maintain homeostasis $(61,62)$. The observed monocytic infiltration is attributed to the breakdown and weakening of the blood-brain barrier, which then facilitates the entrance of immune cells (63, 64). However, while monocyte infiltration has traditionally been considered a late event in disease development recent studies by Yamasaki et al. using an EAE model, demonstrated that infiltration of Ly $6 \mathrm{C}^{+}$monocytes occurs at the onset of disease and that these infiltrating cells are responsible for initiating nodal demyelination (65). It was further demonstrated that, while infiltrating monocytes are responsible for initiating nodal demyelination, resident microglia are relatively quiescent upon disease onset (65-67). The infiltrating monocytes promote disease progression though they do not appear to contribute to the resident microglial population (68). Similarly in a model of AD immune cell infiltration and localization of microglial populations in areas of amyloid $\beta(\mathrm{A} \beta)$ plaque deposits has been observed $(69,70)$.

Recently, researchers have been targeting microglial genes, such as TGF- $\beta$ activated kinase (TAK1) to elucidate how tissue-resident macrophages are behaving during inflammation. While infiltrating monocytes are highly phagocytic and inflammatory, resident microglia are relatively quiescent upon disease onset. However, a recent study by Goldmann et al. demonstrated an essential role of microglia in the onset and progression of disease in an EAE model (71). By targeting TAK1 in microglia, but not peripheral monocytes/macrophages, they found that the lack of TAK1 in microglia inhibited the progression of inflammation in the CNS, highlighting the contribution of both resident microglia and bone marrow-derived monocytes in the onset and progression of EAE. However, in a model of EAE, infiltrating monocytes are not maintained and do not appear to contribute to the resident microglial population (68). Furthermore, recent studies using intravital correlated microscopy in zebrafish show that infiltrating phagocytes undergo cell death and are engulfed by resident microglia during resolution of inflammation (72). Popovich et al. investigated the potential for targeting $\mathrm{CX}_{3} \mathrm{CR} 1$ in a model of SCI as the ligand-receptor interactions between $\mathrm{CX}_{3} \mathrm{CR} 1$ and $\mathrm{CX}_{3} \mathrm{CL} 1$ are fundamental for optimal microglial function (47). Furthermore, Donelly et al. presented two important findings, targeted $\mathrm{CX}_{3} \mathrm{CR} 1$ deficiency/blocking in SCI results in enhanced recovery and decreased monocytic infiltration to injury site (48).

\section{ADIPOSE TISSUE MACROPHAGES}

While it has long been clear that undernutrition can impair immunocompetence, more recently, the progression of obesity has also been attributed to a shift in immune function from an M2 to M1 type responses (73). Work by both Spiegelman $(74,75)$ and Lumeng et al. demonstrate critical interactions between adipose tissue metabolism and the immune system, and the active role of adipose tissue macrophage (ATM) polarization in the progression of obesity. Lean individuals in a non-inflammatory state maintain a relatively low percentage $(\sim 10-15 \%)$ of resident ATMs (76). Healthy adipose tissue consists of uniformly distributed alternatively activated M2 macrophages, expressing Arg1 and the cell surface antigens CD206 and CD301 (Figure 3) (77-79). The M2 polarized state of the ATM population in healthy adipose tissue is maintained by eosinophils (80), which secrete IL-4 (Figure 3) $(81,82)$. Polarized M2 ATMs secrete interleukin-10 (IL-10), which regulates glucose homeostasis within adipose tissue and systemic tissues including muscle (Figure 3) (83). In turn adipose resident invariant natural killer T cells (iNKT), expressing nuclear factor interleukin 3 regulated (E4BP4), induces the M2 phenotype through secretion of IL-10 (84). Healthy adipocytes, in turn, secrete anti-inflammatory adipokines such as adiponectin, a hormone that acts synergistically with IL- 4 to exert anti-inflammatory effects through the activation of AMP kinase (AMPK) and signal transducer and activator of transcription 6 (STAT6), respectively $(78,85,86)$. The alternative M2 state is further sustained by the transcriptional regulators peroxisome proliferator-activated receptor- $\delta$ (PPAR $\delta$ ), PPAR $\gamma$, and Krüppel-like factor 4 (KLF4) (82, 87-89).

The intimate interaction between adipocytes and ATMs may reflect a common origin of these two cell types. Studies have shown not only cross-talk between ATMs and adipocytes, but a great deal of plasticity between these two lineages compartments $(90,91)$. Furthermore, while still controversial (92) several studies have suggested that some adipocytes and adipose progenitors may be hematopoietic stem cell-derived $(93,94)$. In addition, Coussin et al. have shown that hematopoietic stem cells that can reconstitute lethally irradiated recipient mice exist within adipose tissue (95), and more recent studies have supported the concept that adipose tissue is an extramedullary source of hematopoietic stem/progenitor cells $(96,97)$. Yet other studies have demonstrated the phagocytic capacity of pre-adipocytes and adipocytes suggesting they can adopt macrophage-like functions $(85,98)$. Interestingly, a recent study by Eto et al. has identified a novel subpopulation of ATMs present in perivascular regions of adipose tissue (99). This population of ATMs is characterized by the expression of CD206 and the stem cell marker CD34. The investigators further demonstrated that these cells can differentiate into the adipogenic lineage in vitro, suggesting the possibility that this subpopulation of ATMs might be a source of adipocytes in vivo. Whether these cells are hematopoietic-derived or whether they are precursors of the more abundant $\mathrm{CD} 206^{+} \mathrm{CD} 34^{-}$ATMs is unclear.

In the late 2000s, Lumeng et al. identified adipose tissue inflammation as an important early event in the development of obesity related complications (82). At the onset of environmental and 


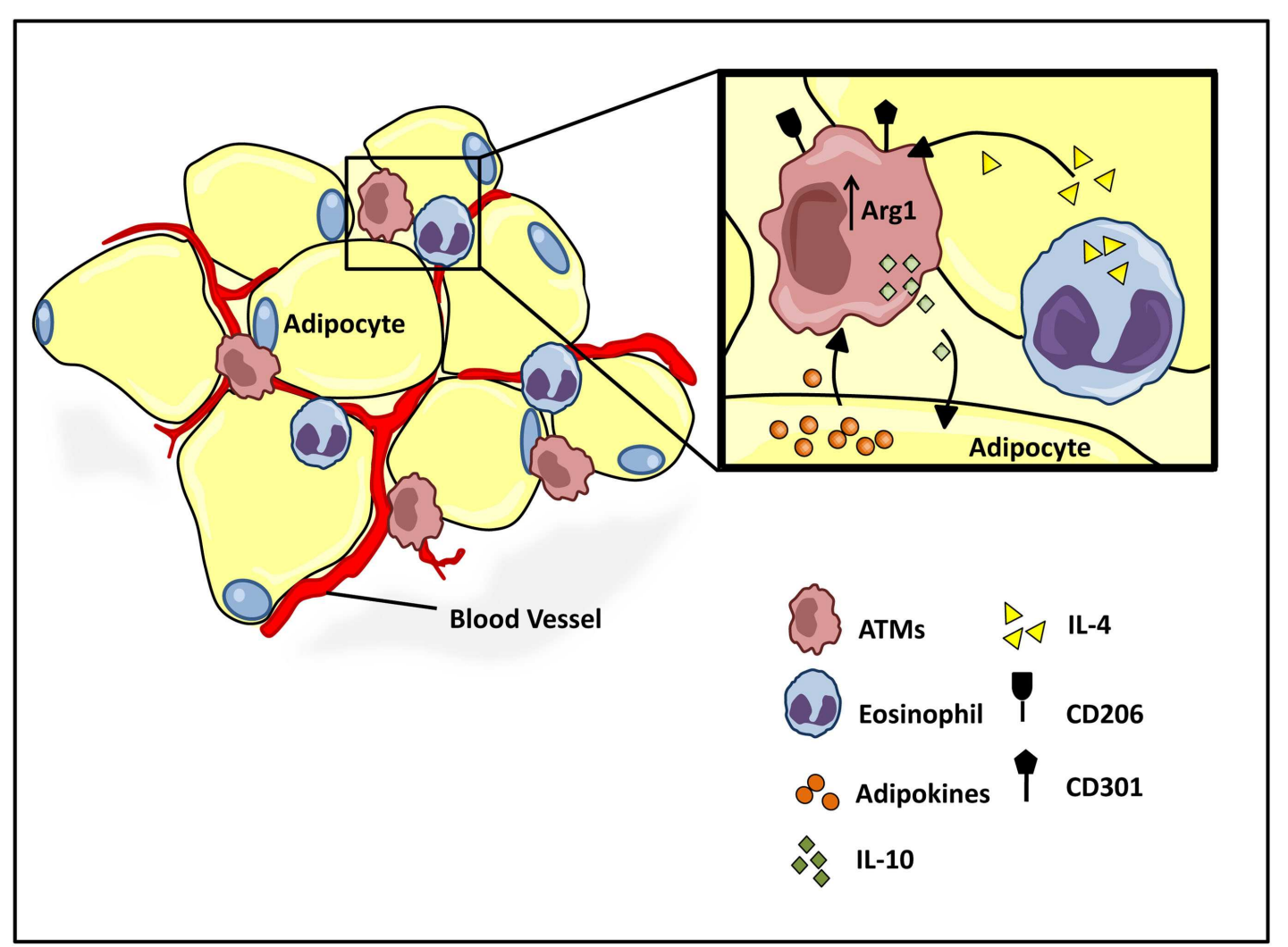

FIGURE 3 | Homeostatic regulation of ATM microenvironment. Healthy adipose tissue contains a relatively low and uniformly dispersed population of alternatively activated $\mathrm{M} 2$ macrophages, expressing cell surface antigens CD206 and CD301. The M2 polarized state is maintained by eosinophil and adipocyte derived adipokine secretions, IL-4, and adiponectin, respectively. M2 ATMs maintain a homeostatic adipose milieu with IL-10 secretions, which in turn regulate glucose homeostasis within systemic tissues. metabolic perturbation, such as chronic exposure to a high-fat diet (HFD), adipose tissue undergoes vast biochemical and morphological remodeling in part facilitated by infiltrating monocytes that then differentiate into ATMs. An excess of nutrients stimulates adipose tissue hyperplasia and hypertrophy as individual adipocytes enlarge with excess triglycerides (TAGs) and simultaneously undergo heightened levels of cellular stress imparted by endoplasmic reticular (ER) stress, hypoxia, release of excess free fatty acids (FFAs), increased reactive oxygen species (ROS) production, and adipocyte necrosis $(77,82,100)$. The "stressed adipocytes" create an environmental milieu that promotes a more pro-inflammatory state exemplified with an increase in local IL-6, $\mathrm{TNF} \alpha$, and IL-1 production (101). Early adipocyte death is facilitated by ATMs in an effort to maintain homeostasis, followed by the development of a new range of pre-adipocytes $(77,102)$. Further studies demonstrated that adipocyte necrosis is not only an early event in diet-induced obesity (DIO), but it is a pivotal event, which results in the release of chemokines that attract circulating monocytes to the site of inflammation $(101,103)$. It is well established that throughout the course of adipose tissue inflammation, the resident macrophage population increases from $\sim 10$ to $50-60 \%$ associated with a parallel increase in $\mathrm{F} 4 / 80^{+} \mathrm{CD} 11 \mathrm{c}^{+}$ inflammatory macrophages $(78,82)$. Interestingly, Kosteli et al. demonstrated that weight loss also leads to a rapid recruitment and accumulation of ATM's in white adipose tissue (WAT) (104). ATM accumulation occurs with lipolysis-induced release of excessive FFAs and subsequent clearance of lipolysis byproducts by WAT macrophages. Contrary to DIO ATM accumulation, weight loss induced ATM recruitment does not exacerbate the existing inflammatory state and ATM populations diminish with the declining rate of lipolysis (105).

At the onset of a physiological imbalance in the adipose niche, such as weight gain, the uniformly dispersed small population of resident macrophages exhibits an alternatively activated CD206 ${ }^{+} \mathrm{CD}_{301}{ }^{+} \mathrm{Arg} 1^{+} \mathrm{M} 2$ phenotype $(79,82,87)$. The ensuing pro-inflammatory milieu created by stressed adipocytes and necrosis attracts circulating monocytes to the site of inflammation as early as 10 weeks from the onset of HFD introduction. Circulating Ly6C ${ }^{+} /$chemokine receptor-2 (CCR2) ${ }^{+}$monocytes are recruited and differentiate into the classically activated

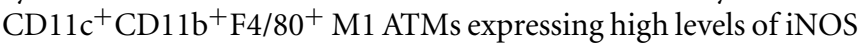
and $\mathrm{TNF} \alpha(78,106)$. Cinti et al. demonstrated that the differentiated M1 ATMs are exclusively localized in epididymal white adipose tissue (eWAT) and not inguinal white adipose tissue (iWAT), more specifically within "crown-like structures (CLS)" composed of necrotic adipocytes (107). The authors incorporated a HSL ${ }^{-1-}$ 
(hormone sensitive lipase $\mathrm{KO}$ ) model to show that adipocyte hypertrophy itself triggers a pro-inflammatory microenvironment that facilitates infiltration of monocytes (107). The M1 monocytederived macrophages are recruited and stabilized by CCR2 and its ligand CCL2 in addition to other factors such as osteopontin and fatty acids (FAs) $(78,106)$. CCL2 loss of function as well as CCR2 gain of function or overexpression studies have collectively illustrated the fundamental role of CCR2 and CCL2 in recruitment and differentiation of macrophages with an $\mathrm{M} 1$ phenotype $(78,85)$. However, Amano et al. recently demonstrated that local proliferation of ATMs contributes significantly to tissue ATM accumulation. They further demonstrated that this in situ proliferation is driven by monocyte chemotactic protein (MCP-1) (108). These studies highlight the contribution of both local proliferation and infiltrating monocytes to the accumulation of ATMs in an obesity induced inflammatory state $(108,109)$.

While the observed ATM increase associated with obesity is predominantly attributed to macrophages exhibiting an M1 phenotype, Shaul et al. recently suggested that there exists an M1/M2 hybrid ATM population and that the increase in ATMs with obesity exhibit more of this mixed phenotype. The study noted an increase in both M1 and M2 gene transcripts in a mouse DIO model of chronic inflammation suggesting that perhaps both populations may influence the progression of obesity-associated chronic inflammation (103). However, despite transcriptional increases in both M1 and M2 genes, further studies by the authors demonstrated an overall decrease in the M2 populations in the DIO model as exhibited by flow cytometry analysis of eWAT cells expressing macrophage galactose type-C lectin-1 (MGL1, also known as CD301). It is not clear whether this intermediate population of ATMs represents a truly separate population of cells or whether these ATMs represent a transitional population, resulting from the inherent plasticity of ATM phenotypes in vivo.

In healthy adipose tissue, tissue remodeling is accompanied by angiogenesis to maintain oxygen supply and critical nutrients to promote adipose tissue homeostasis. However, under pathological conditions, the existing adipocytes enlarge, angiogenesis is limited, and tissue hypoxia ensues, resulting in the recruitment of inflammatory cells. Angiogenesis is induced by vascular endothelial factor-A (VEGF-A) stimulation of vascular endothelial growth factor receptor-2 (VEGFR-2) (110,111). When VEGFR-2 is blocked early in the onset of obesity, the development of metabolic disorders is elevated suggesting that expanding vascularization can promote diet-induced disease (112). However, Elias et al. demonstrated that overexpression of VEGF-A in adipose tissue in a DIO model promotes the maintenance of a larger M2 population and attenuates adipose tissue inflammation (113), coinciding with an increase in local blood flow and decreased presence of necrotic CLS. The authors further conclude that the correlative increase in VEGF and M2 macrophage populations is likely due to recruitment of M2 macrophages to sites of inflammation in adipose tissue rather than promoting a phenotypic switch between $\mathrm{M} 1$ and M2 macrophage populations. Recent studies also demonstrate an increase in brown adipose tissue thermogenesis as a response to cold, particularly in the presence of VEGF overexpression (113, 114). Interestingly, pivotal studies in by the Chawla lab demonstrated that the absence of alternatively activated M2 macrophages results in impaired metabolic adaptation to cold, while administration of IL-4 promotes adaptation in a macrophage-dependent manner (115), suggesting that the increased thermogenesis in response to cold in the presence of VEGF could also be mediated, at least in part, by M2 macrophages.

Therapeutic strategies in obesity and obesity-associated disease may lie in understanding the molecular underpinnings of tissueresident macrophage heterogeneity. For instance, loss of KLF4 function has been associated with a loss of wound healing capacities under inflammatory conditions suggesting an important role for KLF4 in maintaining an M2 phenotype in vivo (87). In addition to KLF4, differential expression of PPAR $\delta$ and PPAR $\gamma$ in current experimental models, including HFD-induced obesity, illustrate a critical role for activated PPARs in directing monocytic infiltration and polarization of macrophages toward the alternative state in adipose tissue and liver $(116,117)$. Genetic deletion of $\operatorname{PPAR} \delta$ and/or PPAR $\gamma$ in macrophages directs the differentiation of monocytes toward a pro-inflammatory M1 phenotype $(88,118)$. Conversely, agonist mediated PPAR-activation stimulates monocytic differentiation into an alternately activated M2 phenotype (119). These agonists include synthetic anti-diabetic agents such as Thiazolidinediones (TZD) or natural agents such as abscisic acid (ABA) $(116,119,120)$. Recent studies by Satoh et al. have demonstrated an essential role for the pseudokinase, Trib1, in the development of M2-like macrophage populations. Mice lacking Trib1 in the hematopoietic cell compartment exhibit a severe reduction in M2-like macrophages in a number of tissues under homeostatic conditions (121). In addition, these mice also exhibit a significant reduction in eosinophils, suggesting that the defect in M2 polarization could be, in part, secondary to diminished levels of eosinophil-derived IL-4 under homeostatic conditions. Importantly, these mice develop hypertriglyceridemia and insulin resistance when maintained on a HFD, associated with increased expression of pro-inflammatory cytokines $(121,122)$.

\section{KUPFFER CELLS (LIVER-RESIDENT MACROPHAGES)}

One of the largest resident populations of macrophages exists in the liver. These YS macrophages, termed Kupffer cells, are positioned in the liver sinusoids where they efficiently clear microbes and apoptotic cells from the portal circulation (Figure 4) (123). While the proliferative capacity of hepatic macrophages remains controversial, recent studies have suggested that Kupffer cells are established prenatally and are maintained into adulthood independent of replenishment from blood monocytes in a manner dependent on M-CSF and GM-CSF (9). Kupffer cells also play essential roles in tissue homeostasis, tissue remodeling, and regulation of metabolic function in the liver (Figure 4). Due to their constant exposure to blood-borne food antigens and bacterial products of commensal intestinal flora, these cells are also required to prevent the onset of inflammation in response to these non-pathogenic stimuli (124). In contrast, monocytederived macrophages in the liver play dual roles in promoting both tissue inflammation and repair. These infiltrating cells are initially $\mathrm{CD} 11 \mathrm{~b}^{+} \mathrm{F} 4 / 80^{+}$and eventually differentiate into more mature $\mathrm{CD} 11 \mathrm{~b}^{\text {lo }} \mathrm{F} 4 / 80^{\text {hi }}$ macrophages.

Following acute hepatic injury induced by acetaminophen, there is a large influx of monocyte-derived macrophages induced 


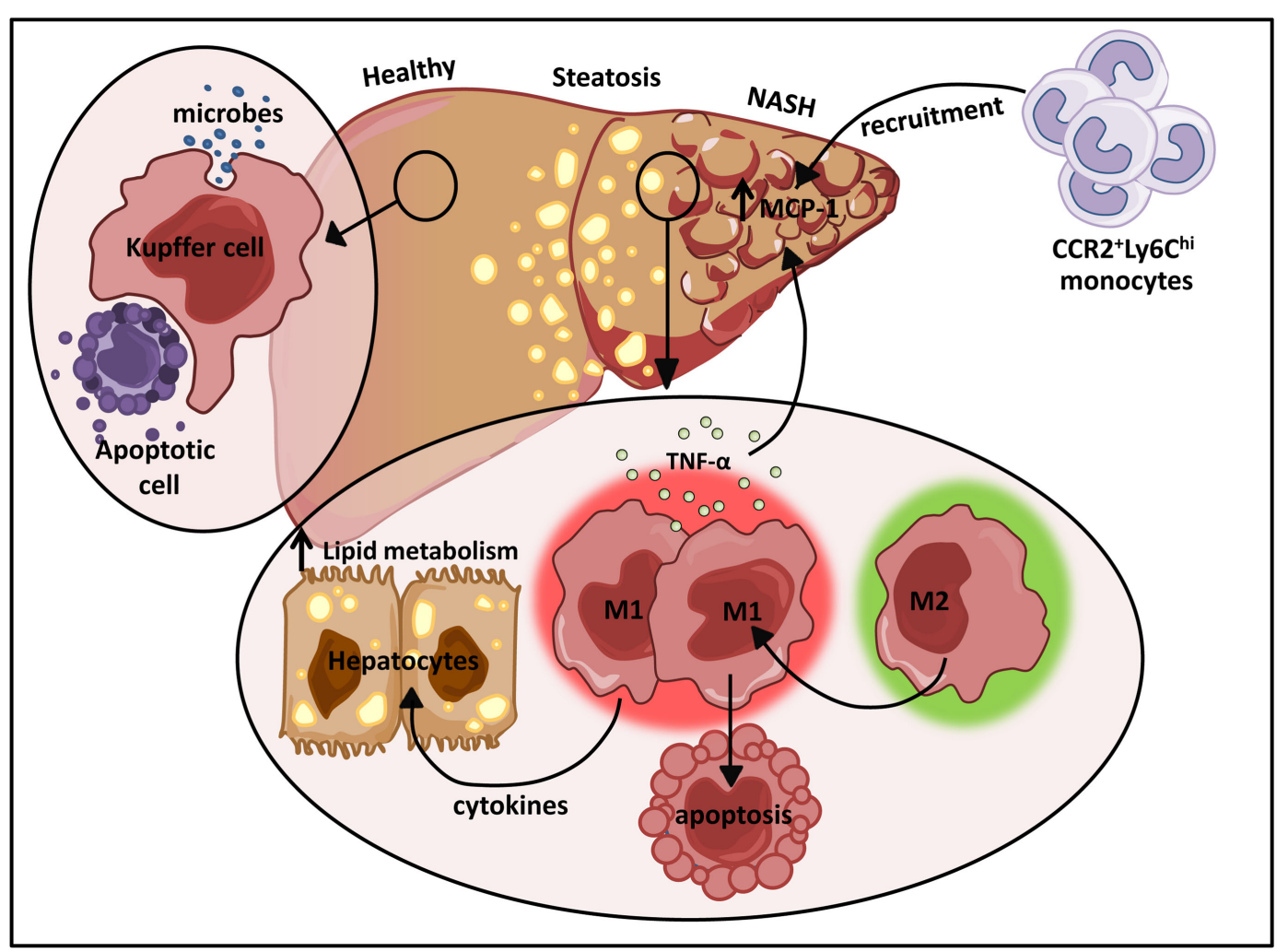

FIGURE 4 |The dual role of M1/M2 Kupffer cells in NAFLD. Kupffer cells play a pivotal role in host defense where they routinely clear microbes and apoptotic bodies from portal circulation. During diet-induced liver injury, tissue-resident macrophages exhibiting a classically activated $\mathrm{M} 1$ phenotype predominate and secrete cytokines that can alter hepatocyte lipid metabolism and induce MCP-1 dependent recruitment of monocytes into the liver. In turn, these infiltrating cells facilitate the development and progression of NAFLD. Restrained induction of M1 Kupffer cell apoptosis further perpetuates liver inflammation. by CCL2, accompanied by a significant decrease in the resident population of Kupffer cells (125-127). This influx is blocked in CCR2-deficient mice and these mice exhibit a delay in tissue recovery indicating that the infiltrating population of macrophages plays an important role in promoting liver repair following an acute insult $(126,127)$. However, when both infiltrating hepatic macrophages and resident Kupffer cells are depleted, tissue recovery is dramatically impaired $(126,128)$. These mice exhibited impaired clearance of necrotic cells and a defect in the restoration of the liver microvasculature $(126,128)$. During the resolution phase of acute inflammation, the infiltrating monocyte-derived cells differentiate into the more mature reparative macrophages and the resident Kupffer cell population is restored. Genomic analysis of these co-existing populations of cells demonstrated that, while the recovered Kupffer cell population was similar to resident Kupffer cells before injury, these cells were distinct from the resolution phase monocyte-derived liver macrophage population, suggesting that these populations have distinct functions in liver recovery from acute inflammation and that the infiltrating monocyte-derived macrophages do not replace the resident Kupffer cells (126).

Non-alcoholic fatty liver disease is the most common liver disease in the western world, the prevalence of which has increased in parallel to the increased incidence of obesity $(129,130)$. This clinicopathological condition is characterized by lipid accumulation in hepatocytes and ranges from the non-progressive form termed steatosis to non-alcoholic steatohepatitis (NASH), the progressive form that is prone to the development of cirrhosis, liver cancer, and liver failure $(130,131)$. In response to obesity, Kupffer cells are engaged by cytokines, adipokines, and FAs secreted from adipose tissue promoting a polarized M1 phenotype (132). In addition, the release of FFAs into the liver by hypertrophic adipocytes leads to hepatocyte ER stress and ROS production (132). Hepatocyte death triggered by these responses results in the release of danger associated molecular patterns (DAMPs) that further promote liver macrophage polarization $(123,132)$.

In hepatic steatosis, pro-inflammatory cytokines produced by M1 activated macrophages induce hepatic cholesterologenesis and increase TAG production, resulting in discordant regulation of lipid metabolism and homeostasis (Figure 4) (133-136). Sterol regulatory element-binding proteins (SREBPs) directly activate genes that mediate the synthesis and uptake of cholesterol and FAs (137). Elevation of SREBPs often underlies the pathogenesis of insulin resistance and type 2 diabetes $(138,139)$. In addition to their initial propagation of fatty liver disease, activated M1 Kupffer cells trigger the more severe form of non-alcoholic fatty liver 
disease (NAFLD), NASH. A recent study demonstrated that TNF $\alpha$ produced by M1 hepatic macrophages increased intrahepatic expression of MCP-1 (Figure 4), a major chemokine responsible for CCR2-dependent recruitment of Ly6 $\mathrm{C}^{\text {hi }}$ monocytes (135). The vast infiltration of Ly6 $\mathrm{C}^{\text {hi }}$ monocytes further perturbs liver homeostasis amplifying hepatic inflammatory responses (Figure 4). The recruited monocyte-derived macrophage population also plays a key role in promoting fibrogenesis. In mice deficient for CCR2 or depleted of Kupffer cells, inflammatory cell infiltration, steatohepatitis, and fibrosis are ameliorated (135).

Progression of NAFLD to NASH occurs in a subset of patients with fatty liver disease, and this progression is largely linked to the activation of toll like receptor 4 (TLR4) by both exogenous and endogenous ligands. Bacteria and bacterial products, such as LPS, which translocate from the gut can activate TLR4 signaling to induce NASH $(140,141)$. Furthermore, endogenous high mobility group box-1 (HMGB-1) and FFAs have also been shown to be endogenous ligands for TLR4 $(142,143)$. A number of recent studies have also demonstrated a crucial link between the composition of gut microbiota, obesity, and the development of NASH (144). CD14 promotes the activation of TLR4 by promoting the recruitment of LPS to the TLR4 signaling complex (145). Interestingly, Imajo et al. demonstrated that the increased levels of leptin associated with obesity promotes the enhanced expression of CD14 in Kupffer cells, resulting in increased sensitivity of the Kupffer cells to low doses of LPS (146). Translocated bacterial DNA has also been shown to promote the development of NASH through engagement of TLR9 in Kupffer cells, which stimulates the production of interleukin-1 $\beta$ (IL-1 $\beta$ ) (147). IL-1 $\beta$ in turn, promotes hepatocyte lipid accumulation and death, as well inducing hepatic stellate cells (HpSCs) to promote fibrosis.

Liver fibrosis is a common feature of chronic liver disease. It is characterized by accumulation of extracellular matrix (ECM) resulting from both increased synthesis and decreased degradation of ECM proteins (148). During progressive liver injury, HpSCderived myofibroblast-like cells predominate and initiate collagen deposition (148). Extensive evidence demonstrates a complex interplay between Kupffer cells and HpSCs during hepatic fibrogenesis. In general, alternatively activated M2 macrophages are involved in tissue remodeling through the production of transforming growth factor beta-1 (TGF $\beta-1)$, a potent inducer of the HpSC fibrotic phenotype $(149,150)$. However, while arginase produced by M2 cells during a Th2 response was thought to play a role in progression of fibrosis, studies by Pesce et al., in which arginase is depleted in macrophages, highlight a role for arginase-expressing macrophages in the resolution of fibrosis (151). Alternatively, in hepatic fibrosis, Ly6C ${ }^{\text {hi }}$ inflammatory monocyte-derived macrophages express higher levels of TGF $\beta$ 1 and other pro-inflammatory cytokines that activate HpSCs (152). TGF $\beta$-1 not only promotes the fibrogenic activity of HpSCs but also enhances expression of tissue inhibitors of metalloproteinases (TIMPs) by HpSCs that block the degradation of ECM. These inflammatory monocyte-derived macrophages also exhibit decreased expression of matrix metalloproteinases, thus directly promoting fibrosis.

Interestingly, a recent report demonstrated a role for a novel population of monocyte-derived macrophages in the resolution of fibrosis. These cells are derived from Ly6 $\mathrm{C}^{\text {hi }}$ monocytes and exhibit a CD11b ${ }^{\text {hi }} 4 / 80^{\text {int }}{\text { Ly } 6 C^{\text {lo }}}$ phenotype. These cells mediate MMP-dependent degradation of the ECM and the expression profile of this population of resolving monocyte-derived macrophages demonstrates that these cells are distinct from the typical M1/M2 populations of macrophages (152). More recently, it has been reported that alternatively activated M2 Kupffer cells can promote caspase-3-dependent apoptosis of classically activated M1 Kupffer cells, thus providing a protective mechanism against NAFLD (Figure 4) (153). The M2 mediated apoptosis of M1 Kupffer cells was shown to be arginase dependent by way of IL-10 (153). Interestingly, alternatively activated M2 Kupffer cells limit hepatocyte apoptosis and steatosis in alcohol induced liver injury through the release of IL-6, a mechanism that may expand to NAFLD (154).

\section{SUMMARY}

Based on recent studies, a unifying theme is beginning to emerge between the contribution of tissue-resident macrophages and infiltrating monocyte-derived macrophages in chronic inflammation (Figure 5). (1) Both microglia and Kupffer cells are of embryonic origin. Microglia are YS, while contribution of yolk sac and fetal liver has been described for Kupffer cells. However, because it now appears that the yolk sac progenitors seed the liver where they continue to contribute to tissue-resident macrophage populations independent of hematopoietic stem cells, it is likely that these cells share a common progenitor and are ontologically indistinguishable. (2) In the brain and liver, resident macrophages and infiltrating monocyte-derived macrophages play distinct roles in the progression of inflammation. In the brain, microglia are required for the initiation of disease, while infiltrating monocytederived macrophages promote demyelination. In the liver, both resident and infiltrating populations contribute to both inflammation and repair, Kupffer cells are largely responsible for the development of fibrosis. (3) In the brain and liver, infiltrating monocytes do not contribute to the resident macrophage pool rather, during recovery, resident cells are replenished through local proliferation. (4) In both the brain and liver, there is evidence that the resident population of macrophages plays a role in promoting apoptosis and/or clearance of the infiltrating monocyte-derived macrophage population during the recovery phase.

However, the relative contribution of resident versus infiltrating populations of macrophages in adipose tissue remains obscure. While ATMs are generally considered to be hematopoietic stem cells-derived, this assumption is based on studies using myeloablation. Further fate mapping studies will be needed to definitively identify the origin of ATMs. In addition, while it is clear that both infiltration of monocytes and proliferation of resident macrophage contribute to the massive expansion of ATMs in obesity, the respective roles of resident versus infiltrating macrophages in the propagation and/or resolution of inflammation is unclear. Finally, it unknown whether infiltrating monocytederived macrophages in adipose tissue ultimately contribute to the resident population.

In all cases, the M1/M2 polarization of macrophages in inflammation and disease resolution has been described. However, these 


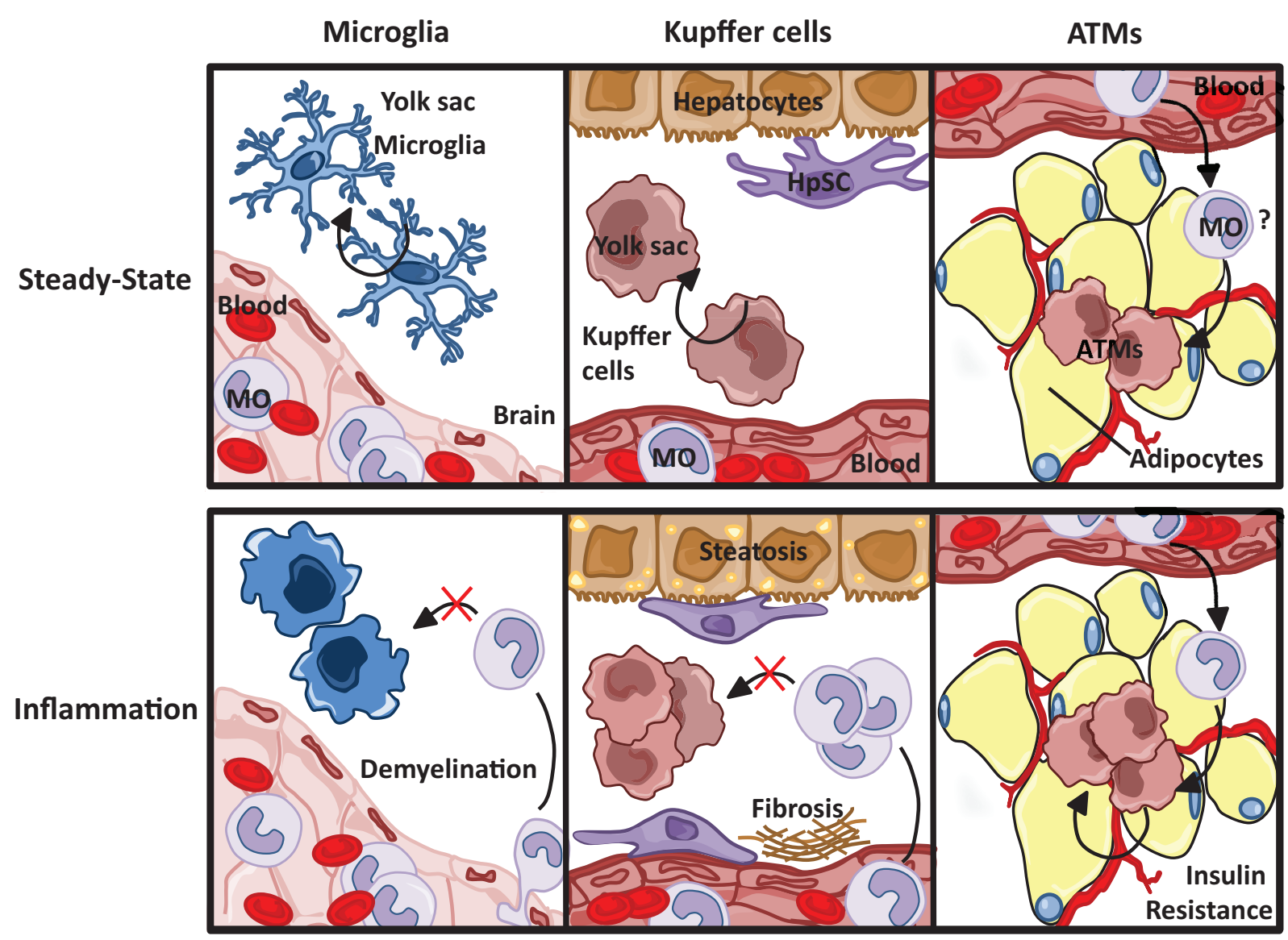

FIGURE 5 | Resident macrophage populations in steady state and inflammation. Resident microglia and Kupffer cell populations, both yolk sac-derived, are maintained through self-renewal, unlike macrophages resident to the adipose tissue, which are thought to originate from circulating blood monocytes (MO). Although the progression of tissue specific pathophysiological insults are dependent on both resident and infiltrating macrophages, monocyte-derived macrophages do not replenish resident microglia and Kupffer cell populations. are largely based on studies that do not distinguish between resident macrophage and infiltrating macrophage populations. Given the emergence of technologies that help to distinguish resident cells from infiltrating cells, it will be essential to re-visit the M1/M2 paradigm in the context of macrophage ontogeny to determine the extent of plasticity of individual populations of macrophages.

The recognition that the M1/M2 polarization of macrophages plays a central role in the progression of chronic inflammation in a wide range of diseases and that therapeutic approaches to chronic inflammatory disease could involve the regulation of macrophage polarization renders these outstanding questions highly significant. Taking into consideration not only the polarization state of macrophages, but also their ontogeny and phenotypic plasticity, will be central in the development of therapeutic approaches for the treatment of chronic inflammatory disease aimed at redirecting macrophage polarization and function.

\section{REFERENCES}

1. Gautier EL, Shay T, Miller J, Greter M, Jakubzick C, Ivanov S, et al. Geneexpression profiles and transcriptional regulatory pathways that underlie the identity and diversity of mouse tissue macrophages. Nat Immunol (2012) 13:1118-28. doi:10.1038/ni.2419
2. Davies LC, Jenkins SJ, Allen JE, Taylor PR. Tissue-resident macrophages. Nat Immunol (2013) 14:986-95. doi:10.1038/ni.2705

3. Chow A, Huggins M, Ahmed J, Hashimoto D, Kunisaki Y, Pinho S, et al. CD169+ macrophages provide a niche promoting erythropoiesis under homeostasis, myeloablation and in JAK2V617F-induced polycythemia vera. Nat Med (2014) 19:429-36. doi:10.1038/nm.3057

4. Haldar M, Kohyama M, So AY-L, Kc W, Wu X, Briseño CG, et al. Hememediated SPI-C induction promotes monocyte differentiation into ironrecycling macrophages. Cell (2014) 156:1223-34. doi:10.1016/j.cell.2014.01. 069

5. Epelman S, Lavine KJ, Randolph GJ. Origin and functions of tissue macrophages. Immunity (2014) 41:21-35. doi:10.1016/j.immuni.2014.06.013

6. Wynn TA, Chawla A, Pollard JW. Macrophage biology in development, homeostasis and disease. Nature (2013) 496:445-55. doi:10.1038/nature12034

7. Ginhoux F, Greter M, Leboeuf M, Nandi S, See P, Gokhan S, et al. Fate mapping analysis reveals that adult microglia derive from primitive macrophages. Science (2010) 330:841-5. doi:10.1126/science.1194637

8. Schulz C, Gomez Perdiguero E, Chorro L, Szabo-Rogers H, Cagnard N, Kierdorf $\mathrm{K}$, et al. A lineage of myeloid cells independent of Myb and hematopoietic stem cells. Science (2012) 336:86-90. doi:10.1126/science.1219179

9. Yona S, Kim KW, Wolf Y, Mildner A, Varol D, Breker M, et al. Fate mapping reveals origins and dynamics of monocytes and tissue macrophages under homeostasis. Immunity (2014) 38:79-91. doi:10.1016/j.immuni.2012.12.001

10. Epelman S, Lavine KJ, Beaudin AE, Sojka DK, Carrero JA, Calderon B, et al. Embryonic and adult-derived resident cardiac macrophages are maintained 
through distinct mechanisms at steady state and during inflammation. Immunity (2014) 40:91-104. doi:10.1016/j.immuni.2013.11.019

11. Heidt T, Courties G, Dutta P, Sager HB, Sebas M, Iwamoto Y, et al. Differential contribution of monocytes to heart macrophages in steady-state and after myocardial infarction. Circ Res (2014) 115:284-95. doi:10.1161/ CIRCRESAHA.115.303567

12. Pinto AR, Godwin JW, Rosenthal NA. Macrophages in cardiac homeostasis, injury responses and progenitor cell mobilisation. Stem Cell Res (2014) 13:705-14. doi:10.1016/j.scr.2014.06.004

13. Hashimoto D, Chow A, Noizat C, Teo P, Beth M, Leboeuf M, et al. Tissue resident macrophages self-maintain locally throughout adult life with minimal contribution from circulating monocytes. Immunity (2014) 38:1-25. doi:10.1016/j.immuni.2013.04.004

14. Bogunovic M, Ginhoux F, Helft J, Shang L, Greter M, Liu K, et al. Origin of the lamina propria dendritic cell network Milena. Immunity (2010) 31:513-25. doi:10.1016/j.immuni.2009.08.010

15. Varol C, Vallon-Eberhard A, Elinav E, Aychek T, Shapira Y, Luche H, et al. Intestinal lamina propria dendritic cell subsets have different origin and functions. Immunity (2009) 31:502-12. doi:10.1016/j.immuni.2009.06.025

16. Perdiguero EG, Klapproth K, Schulz C, Busch K, Azzoni E, Crozet L, et al. Tissue-resident macrophages originate from yolk-sac-derived erythro-myeloid progenitors. Nature (2014). doi:10.1038/nature13989

17. Jenkins SJ, Ruckerl D, Cook PC, Jones LH, Finkelman FD, van Rooijen $\mathrm{N}$, et al. Local macrophage proliferation, rather than recruitment from the blood, is a signature of TH2 inflammation. Science (2011) 332:1284-8. doi:10.1126/science.1204351

18. Jenkins SJ, Ruckerl D, Thomas GD, Hewitson JP, Duncan S, Brombacher F, et al. IL-4 directly signals tissue-resident macrophages to proliferate beyond homeostatic levels controlled by CSF-1. J Exp Med (2013) 210:2477-91. doi:10.1084/jem.20121999

19. Mielcarek M, Kirkorian AY, Hackman RC, Price J, Storer BE, Wood BL, et al. Langerhans cell homeostasis and turnover after nonmyeloablative and myeloablative allogeneic hematopoietic cell transplantation. Transplantation (2014) 98:563-8. doi:10.1097/TP.0000000000000097

20. Cohen HB, Mosser DM. Cardiac macrophages: how to mend a broken heart. Immunity (2014) 40:3-5. doi:10.1016/j.immuni.2013.12.005

21. Rosas M, Davies LC, Giles PJ, Liao C-T, Kharfan B, Stone TC, et al. The transcription factor Gata6 links tissue macrophage phenotype and proliferative renewal. Science (2014) 344:645-8. doi:10.1126/science.1251414

22. Okabe Y, Medzhitov R. Tissue-specific signals control reversible program of localization and functional polarization of macrophages. Cell (2014) 157:832-44. doi:10.1016/j.cell.2014.04.016

23. Schneider C, Nobs SP, Kurrer M, Rehrauer H, Thiele C, Kopf M. Induction of the nuclear receptor PPAR- $\gamma$ by the cytokine GM-CSF is critical for the differentiation of fetal monocytes into alveolar macrophages. Nat Immunol (2014) 15:1026-37. doi:10.1038/ni.3005

24. A-gonzalez N, Guillen JA, Gallardo G, Diaz M, Rosa JV, De Hernandez IH, et al. The nuclear receptor LXR $\alpha$ controls the functional specialization of splenic macrophages. Nat Immunol (2014) 14:831-9. doi:10.1038/ni.2622

25. Ingersoll MA, Spanbroek R, Lottaz C, Gautier EL, Frankenberger M, Hoffmann R, et al. Comparison of gene expression profiles between human and mouse monocyte subsets. Blood (2010) 115:e10-9. doi:10.1182/blood-200907-235028

26. Cros J, Cagnard N, Woollard K, Patey N, Zhang S-Y, Senechal B, et al. Human CD14dim monocytes patrol and sense nucleic acids and viruses via TLR7 and TLR8 receptors. Immunity (2010) 33:375-86. doi:10.1016/j.immuni.2010.08. 012

27. Jakubzick C, Gautier EL, Gibbings SL, Sojka DK, Schlitzer A, Johnson TE, et al. Minimal differentiation of classical monocytes as they survey steady-state tissues and transport antigen to lymph nodes. Immunity (2013) 39:599-610. doi:10.1016/j.immuni.2013.08.007

28. Mills CD, Thomas AC, Lenz LL, Munder M. Macrophage: SHIP of immunity. Front Immunol (2014) 5:1-5. doi:10.3389/fimmu.2014.00620

29. Mills CD, Kincaid K, Alt JM, Heilman MJ, Hill AM. M-1/M-2 macrophages and the Th1/Th2 paradigm. J Immunol (2000) 164:6166-73. doi:10.4049/ jimmunol.164.12.6166

30. Mills CD, Ley K. M1 and M2 macrophages: the chicken and the egg of immunity. J Innate Immune (2014) 6:1716-26. doi:10.1159/000364945
31. Murray PJ, Allen JE, Biswas SK, Fisher EA, Gilroy DW, Goerdt S, et al. Macrophage activation and polarization: nomenclature and experimental guidelines. Immunity (2014) 41:14-20. doi:10.1016/j.immuni.2014.06.008

32. Perry VH, Teeling J. Microglia and macrophages of the central nervous system: the contribution of microglia priming and systemic inflammation to chronic neurodegeneration. Semin Immunopathol (2013) 35:601-12. doi:10. 1007/s00281-013-0382-8

33. Ginhoux F, Jung S. Monocytes and macrophages: developmental pathways and tissue homeostasis. Nat Rev Immunol (2014) 14:392-404. doi:10.1038/nri3671

34. Kierdorf K, Erny D, Goldmann T, Sander V, Schulz C, Perdiguero EG, et al. Microglia emerge from erythromyeloid precursors via Pu.1- and Irf8-dependent pathways. Nat Neurosci (2013) 16:273-80. doi:10.1038/nn. 3318

35. Greter M, Lelios I, Pelczar P, Hoeffel G, Price J, Leboeuf M, et al. Stromaderived interleukin-34 controls the development and maintenance of langerhans cells and the maintenance of microglia. Immunity (2012) 37:1050-60. doi:10.1016/j.immuni.2012.11.001

36. Wang Y, Szretter KJ, Vermi W, Gilfillan S, Rossini C, Cella M, et al. IL-34 is a tissue-restricted ligand of CSF1R required for the development of Langerhans cells and microglia. Nat Immunol (2012) 13:753-60. doi:10.1038/ni.2360

37. Miron VE, Franklin RJM. Macrophages and CNS remyelination. J Neurochem (2014) 130:165-71. doi:10.1111/jnc.12705

38. Ajami B, Bennett JL, Krieger C, Tetzlaff W, Rossi FMV. Local self-renewal can sustain CNS microglia maintenance and function throughout adult life. Nat Neurosci (2007) 10:1538-43. doi:10.1038/nn2014

39. Olah M, Biber K, Vinet J, Boddeke HWGM. Microglia phenotype diversity. CNS Neurol Disord Drug Targets (2011) 10:108-18. doi:10.2174/ 187152711794488575

40. Eggen BJL, Raj D, Hanisch U-K, Boddeke HWGM. Microglial phenotype and adaptation. J Neuroimmune Pharmacol (2013) 8:807-23. doi:10.1007/s11481013-9490-4

41. Kettenmann H, Hanisch U, Noda M, Verkhratsky A. Physiology of microglia. Physiol Rev (2011) 91:461-553. doi:10.1152/physrev.00011.2010

42. Boche D, Perry VH, Nicoll JAR. Review: activation patterns of microglia and their identification in the human brain. Neuropathal Appl Neurobiol (2013) 39:3-18. doi:10.1111/nan.12011

43. Prinz M, Tay TL, Wolf Y, Jung S. Microglia: unique and common features with other tissue macrophages. Acta Neuropathol (2014) 128:319-31. doi:10.1007/s00401-014-1267-1

44. Butovsky O, Jedrychowski MP, Moore CS, Cialic R, Amanda J, Gabriely G, et al. Identification of a unique TGF- $\beta$ dependent molecular and functional signature in microglia. Nat Neurosci (2014) 17:131-43. doi:10.1038/nn.3599

45. Prinz M, Priller J. Microglia and brain macrophages in the molecular age: from origin to neuropsychiatric disease. Nat Rev Neurosci (2014) 15:300-12. doi:10.1038/nrn3722

46. Landsman L, Bar-On L, Zernecke A, Kim K-W, Krauthgamer R, Shagdarsuren $\mathrm{E}$, et al. CX3CR1 is required for monocyte homeostasis and atherogenesis by promoting cell survival. Blood (2009) 113:963-72. doi:10.1182/blood-200807-170787

47. Donnelly DJ, Longbrake EE, Shawler TM, Kigerl KA, Lai W, Tovar CA, et al. Deficient CX3CR1 signaling promotes recovery after mouse spinal cord injury by limiting the recruitment and activation of Ly6Clo/iNOS+ macrophages. $J$ Neurosci (2011) 31:9910-22. doi:10.1523/JNEUROSCI.2114-11.2011

48. Wolf Y, Yona S, Kim K-W, Jung S. Microglia, seen from the CX3CR1 angle. Front Cell Neurosci (2013) 7:26. doi:10.3389/fncel.2013.00026

49. Billadeau DD, Leibson PJ. ITAMs versus ITIMs: striking a balance during cell regulation. J Clin Invest (2002) 109:161-8. doi:10.1172/JCI200214843

50. Linnartz B, Neumann H. Microglial activatory (immunoreceptor tyrosinebased activation motif)- and inhibitory (immunoreceptor tyrosine-based inhibition motif)-signaling receptors for recognition of the neuronal glycocalyx. Glia (2013) 61:37-46. doi:10.1002/glia.22359

51. Lambertsen KL, Deierborg T, Gregersen R, Clausen BH, Wirenfeldt M, Nielsen $\mathrm{HH}$, et al. Differences in origin of reactive microglia in bone marrow chimeric mouse and rat after transient global ischemia. J Neuropathol Exp Neurol (2011) 70:481-94. doi:10.1097/NEN.0b013e31821db3aa

52. Bechmann I, Priller J, Kovac A, Böntert M, Wehner T, Klett FF, et al. Immune surveillance of mouse brain perivascular spaces by blood-borne macrophages. Eur J Neurosci (2001) 14:1651-8. doi:10.1046/j.0953-816x.2001.01793.x 
53. Cherry JD, Olschowka JA, O’Banion MK. Neuroinflammation and M2 microglia: the good, the bad, and the inflamed. J Neuroinflammation (2014) 11:98. doi:10.1186/1742-2094-11-98

54. Varnum MM, Ikezu T. The classification of microglial activation phenotypes on neurodegeneration and regeneration in Alzheimer's disease brain. Arch Immunol Ther Exp (2012) 60:251-66. doi:10.1007/s00005-0120181-2

55. Amor S, Peferoen LAN, Vogel DYS, Breur M, van der Valk P, Baker D, et al. Inflammation in neurodegenerative diseases - an update. Immunology (2014) 142:151-66. doi:10.1111/imm.12233

56. Walker FR, Beynon SB, Jones KA, Zhao Z, Kongsui R, Cairns M, et al. Dynamic structural remodelling of microglia in health and disease: a review of the models, the signals and the mechanisms. Brain Behav Immun (2014) 37:1-14. doi:10.1016/j.bbi.2013.12.010

57. Eggen BJL, Raj D, Hanisch U. Microglial phenotype and adaptation. J Neuroimmune Pharmacol (2013) 8:807-23. doi:10.1007/s11481-013-9490-4

58. Crain JM, Nikodemova M, Watters JJ. Microglia express distinct M1 and M2 phenotypic markers in the postnatal and adult central nervous system in male and female mice. J Neurosci Res (2013) 91:1143-51. doi:10.1002/jnr.23242

59. Streit WJ, Conde JR. Microglia in the aging brain. J Neuropathol Exp Neurol (2006) 65:199-203. doi:10.1097/01.jnen.0000202887.22082.63

60. Streit WJ, Xue Q-S. Microglial senescence. CNS Neurol Disord Drug Targets (2013) 12:763-7. doi:10.2174/18715273113126660176

61. Rezai-Zadeh K, Gate D, Town T. CNS infiltration of peripheral immune cells: d-day for neurodegenerative disease? J Neuroimmune Pharmacol (2009) 4:462-75. doi:10.1007/s11481-009-9166-2

62. Jiang Z, Jiang JX, Zhang G-X. Macrophages: a double-edged sword in experimental autoimmune encephalomyelitis. Immunol Lett (2014) 160:17-22. doi:10.1016/j.imlet.2014.03.006

63. Buckman LB, Hasty AH, Flaherty DK, Buckman CT, Thompson MM, Matlock BK, et al. Obesity induced by a high-fat diet is associated with increased immune cell entry into the central nervous system. Brain Behav Immun (2014) 35:33-42. doi:10.1016/j.bbi.2013.06.007

64. Tucsek Z, Toth P, Sosnowska D, Gautam T, Mitschelen M, Koller A, et al. Obesity in aging exacerbates blood-brain barrier disruption, neuroinflammation, and oxidative stress in the mouse hippocampus: effects on expression of genes involved in beta-amyloid generation and Alzheimer's disease. J Gerontol A Biol Sci Med Sci (2013) 69:1212-26. doi:10.1093/gerona/glt177

65. Yamasaki R, Lu H, Butovsky O, Ohno N, Rietsch AM, Cialic R, et al. Differential roles of microglia and monocytes in the inflamed central nervous system. J Exp Med (2014) 211:1533-49. doi:10.1084/jem.20132477

66. Jung S, Schwartz M. Non-identical twins - microglia and monocyte-derived macrophages in acute injury and autoimmune inflammation. Front Immunol (2012) 3:89. doi:10.3389/fimmu.2012.00089

67. Vainchtein ID, Vinet J, Brouwer N, Brendecke S, Biagini G, Biber K, et al. In acute experimental autoimmune encephalomyelitis, infiltrating macrophages are immune activated, whereas microglia remain immune suppressed. Glia (2014) 62:1724-35. doi:10.1002/glia.22711

68. Ajami B, Bennett JL, Krieger C, McNagny KM, Rossi FMV. Infiltrating monocytes trigger EAE progression, but do not contribute to the resident microglia pool. Nat Neurosci (2011) 14:1142-9. doi:10.1038/nn.2887

69. Jimenez S, Baglietto-Vargas D, Caballero C, Moreno-Gonzalez I, Torres $\mathrm{M}$, Sanchez-Varo R, et al. Inflammatory response in the hippocampus of PS1M146L/APP751SL mouse model of Alzheimer's disease: age-dependent switch in the microglial phenotype from alternative to classic. JNeurosci (2008) 28:11650-61. doi:10.1523/JNEUROSCI.3024-08.2008

70. Yi C-X, Tschöp MH, Woods SC, Hofmann SM. High-fat-diet exposure induces IgG accumulation in hypothalamic microglia. Dis Model Mech (2012) 5:686-90. doi:10.1242/dmm.009464

71. Goldmann T, Wieghofer P, Müller PF, Wolf Y, Varol D, Yona S, et al. A new type of microglia gene targeting shows TAK1 to be pivotal in CNS autoimmune inflammation. Nat Neurosci (2013) 16:1618-26. doi:10.1038/nn.3531

72. Van Ham TJ, Brady CA, Kalicharan RD, Oosterhof N, Kuipers J, Veenstra-Algra A, et al. Intravital correlated microscopy reveals differential macrophage and microglial dynamics during resolution of neuroinflammation. Dis Model Mech (2014) 7:857-69. doi:10.1242/dmm.014886

73. De Heredia FP, Gómez-Martínez S, Marcos A. Obesity, inflammation and the immune system. Proc Nutr Soc (2012) 71:332-8. doi:10.1017/ S0029665112000092
74. Hotamisligil GS, Shargill S, Spiegelman BM. Adipose expression of tumor necrosis factor - a: direct role in obesity-linked insulin resistance. Science (1993) 259:87-91. doi:10.1126/science.7678183

75. Spiegelman BM, Choy L, Hotamisligil GS, Graves RA, Tontonoz P. Regulation of adipocyte gene expression in differentiation and syndromes of obesity/diabetes. J Biol Chem (1993) 268:6823-6.

76. Schipper HS, Prakken B, Kalkhoven E, Boes M. Adipose tissue-resident immune cells: key players in immunometabolism. Trends Endocrinol Metab (2012) 23:407-15. doi:10.1016/j.tem.2012.05.011

77. Wernstedt Asterholm I, Tao C, Morley TS, Wang QA, Delgado-Lopez F, Wang $\mathrm{ZV}$, et al. Adipocyte inflammation is essential for healthy adipose tissue expansion and remodeling. Cell Metab (2014) 20:103-18. doi:10.1016/j.cmet.2014. 05.005

78. Chawla A, Nguyen KD, Goh YPS. Macrophage-mediated inflammation in metabolic disease. Nat Rev Immunol (2011) 11:738-49. doi:10.1038/nri3071

79. Lumeng CN, DelProposto JB, Westcott DJ, Saltiel AR. Phenotypic switching of adipose tissue macrophages with obesity is generated by spatiotemporal differences in macrophage subtypes. Diabetes (2008) 57:3239-46. doi:10.2337/ db08-0872

80. Wu D, Molofsky AB, Liang HE, Ricardo-Gonzalez RR, Jouihan HA, Bando JK, et al. Eosinophils sustain adipose alternatively activated macrophages associated with glucose homeostasis. Science (2011) 332:243-7. doi:10.1126/science. 1201475

81. Prajeeth CK, Löhr K, Floess S, Zimmermann J, Ulrich R, Gudi V, et al. Effector molecules released by Th1 but not Th17 cells drive an M1 response in microglia. Brain Behav Immun (2014) 37:248-59. doi:10.1016/j.bbi.2014.01.001

82. Lumeng CN, Bodzin JL, Saltiel AR. Obesity induces a phenotypic switch in adipose tissue macrophage polarization. J Clin Invest (2007) 117:175-84. doi:10.1172/JCI29881

83. Nagareddy PR, Kraakman M, Masters SL, Stirzaker RA, Gorman DJ, Grant RW, et al. Adipose tissue macrophages promote myelopoiesis and monocytosis in obesity. Cell Metab (2014) 19:821-35. doi:10.1016/j.cmet.2014.03.029

84. Lynch L, Michelet X, Zhang S, Brennan PJ, Moseman A, Lester C, et al. Regulatory iNKT cells lack expression of the transcription factor PLZF and control the homeostasis of Treg cells and macrophages in adipose tissue. Nat Immunol (2014) 16:85-95. doi:10.1038/ni.3047

85. Gustafson B, Hammarstedt A, Andersson CX, Smith U. Inflamed adipose tissue: a culprit underlying the metabolic syndrome and atherosclerosis. Arterioscler Thromb Vasc Biol (2007) 27:2276-83. doi:10.1161/ATVBAHA.107.147835

86. Steinberg GR, Schertzer JD. AMPK promotes macrophage fatty acid oxidative metabolism to mitigate inflammation: implications for diabetes and cardiovascular disease. Immunol Cell Biol (2014) 92:340-5. doi:10.1038/icb.2014.11

87. Liao X, Sharma N, Kapadia F, Zhou G, Lu Y, Hong H, et al. Krüppel-like factor 4 regulates macrophage polarization. J Clin Invest (2011) 121:2736-49. doi:10.1172/JCI45444

88. Chawla A. Control of macrophage activation and function by PPARs. Circ Res (2010) 106:1559-69. doi:10.1161/CIRCRESAHA.110.216523

89. Fernández-Quintela A, Churruca I, Portillo MP. The role of dietary fat in adipose tissue metabolism. Public Health Nutr (2007) 10:1126-31. doi:10.1017/ S1368980007000602

90. Charrière G, Cousin B, Arnaud E, André M, Bacou F, Penicaud L, et al. Preadipocyte conversion to macrophage. Evidence of plasticity. J Biol Chem (2003) 278:9850-5. doi:10.1074/jbc.M210811200

91. Chazenbalk G, Bertolotto C, Heneidi S, Jumabay M, Trivax B, Aronowitz J, et al. Novel pathway of adipogenesis through cross-talk between adipose tissue macrophages, adipose stem cells and adipocytes: evidence of cell plasticity. PLoS One (2011) 6:e17834. doi:10.1371/journal.pone.0017834

92. Koh YJ, Kang S, Lee HJ, Choi T-S, Lee HS, Cho C-H, et al. Bone marrow-derived circulating progenitor cells fail to transdifferentiate into adipocytes in adult adipose tissues in mice. J Clin Invest (2007) 117:3684-95. doi:10.1172/JCI32504

93. Sera Y, Larue AC, Moussa O, Mehrotra M, James D, Williams CR, et al. Hematpoietic stem cell origin of adipocytes. Exp Hematol (2010) 37:1108-20. doi:10.1016/j.exphem.2009.06.008

94. Crossno JT, Majka SM, Grazia T, Gill RG, Klemm DJ. Rosiglitazone promotes development of a novel adipocyte population from bone marrow-derived circulating progenitor cells. J Clin Invest (2006) 116:3220-8. doi:10.1172/ JCI28510

95. Luche E, Cousin B, Garidou L, Serino M, Waget A, Barreau C, et al. Metabolic endotoxemia directly increases the proliferation of adipocyte precursors 
at the onset of metabolic diseases through a CD14-dependent mechanism. Mol Metab (2013) 2:281-91. doi:10.1016/j.molmet.2013.06.005

96. Poglio S, De Toni-Costes F, Arnaud E, Laharrague P, Espinosa E, Casteilla L, et al. Adipose tissue as a dedicated reservoir of functional mast cell progenitors. Stem Cells (2010) 28:2065-72. doi:10.1002/stem.523

97. Han J, Koh YJ, Moon HR, Ryoo HG, Cho C-H, Kim I, et al. Adipose tissue is an extramedullary reservoir for functional hematopoietic stem and progenitor cells. Blood (2010) 115:957-64. doi:10.1182/blood-2009-05-219923

98. Cousin B, Munoz O, Andre M, Fontanilles AM, Dani C, Cousin JL, et al. A role for preadipocytes as macrophage-like cells. FASEB J (1999) 13:305-12.

99. Eto H, Ishimine H, Kinoshita K, Watanabe-Susaki K, Kato H, Doi K, et al. Characterization of human adipose tissue-resident hematopoietic cell populations reveals a novel macrophage subpopulation with CD34 expression and mesenchymal multipotency. Stem Cells Dev (2013) 22:985-97. doi:10.1089/ scd.2012.0442

100. Manteiga S, Choi K, Jayaraman A, Lee K. Systems biology of adipose tissue metabolism: regulation of growth, signaling and inflammation. Wiley Interdiscip Rev Syst Biol Med (2013) 5:425-47. doi:10.1002/wsbm.1213

101. Strissel KJ, Stancheva Z, Miyoshi H, Perfield JW, Defuria J, Jick Z, et al. Adipocyte death, adipose tissue remodeling, and obesity complications. Diabetes (2007) 56:2910-8. doi:10.2337/db07-0767

102. Lee Y, Thacker RI, Hall BE, Kong R, Granneman JG. Exploring the activated adipogenic niche. Cell Cycle (2014) 13:184-90. doi:10.4161/cc.27647

103. Shaul ME, Bennett G, Strissel KJ, Greenberg AS, Obin MS. Dynamic, M2-Like remodeling phenotypes of $\mathrm{CD} 11 \mathrm{c}+$ adipose tissue macrophages during highfat diet-induced obesity in mice. Diabetes (2010) 59:1171-81. doi:10.2337/ db09-1402

104. Kosteli A, Sugaru E, Haemmerle G, Martin JF, Lei J, Zechner R, et al. Weight loss and lipolysis promote a dynamic immune response in murine adipose tissue. J Clin Invest (2010) 120:3466-79. doi:10.1172/JCI42845

105. Red Eagle A, Chawla A. In obesity and weight loss, all roads lead to the mighty macrophage. J Clin Invest (2010) 120:3437-40. doi:10.1172/JCI44721

106. Chávez-Sánchez L, Espinosa-Luna JE, Chávez-Rueda K, Legorreta-Haquet MV, Montoya-Díaz E, Blanco-Favela F. Innate immune system cells in atherosclerosis. Arch Med Res (2014) 45:1-14. doi:10.1016/j.arcmed.2013.11.007

107. Cinti S, Mitchell G, Barbatelli G, Murano I, Ceresi E, Faloia E, et al. Adipocyte death defines macrophage localization and function in adipose tissue of obese mice and humans. J Lipid Res (2005) 46:2347-55. doi:10.1194/jlr.M500294JLR200

108. Amano SU, Cohen JL, Vangala P, Tencerova M, Nicoloro SM, Yawe JC, et al. Local proliferation of macrophages contributes to obesity-associated adipose tissue inflammation. Cell Metab (2014) 19:162-71. doi:10.1016/j.cmet.2013. 11.017

109. Haase J, Weyer U, Immig K, Klöting N, Blüher M, Eilers J, et al. Local proliferation of macrophages in adipose tissue during obesity-induced inflammation. Diabetologia (2014) 57:562-71. doi:10.1007/s00125-013-3139-y

110. Shibuya M. Vascular endothelial growth factor and its receptor system: physiological functions in angiogenesis and pathological roles in various diseases. J Biochem (2013) 153:13-9. doi:10.1093/jb/mvs136

111. Moens S, Goveia J, Stapor PC, Cantelmo AR, Carmeliet P. The multifaceted activity of VEGF in angiogenesis - implications for therapy responses. Cytokine Growth Factor Rev (2014) 25:473-82. doi:10.1016/j.cytogfr.2014.07.009

112. Sun K, Kusminski CM, Scherer PE. Adipose tissue remodeling and obesity. J Clin Invest (2011) 121:2094-101. doi:10.1172/JCI45887

113. Elias I, Franckhauser S, Ferré T, Vilà L, Tafuro S, Muñoz S, et al. Adipose tissue overexpression of vascular endothelial growth factor protects against diet-induced obesity and insulin resistance. Diabetes (2012) 61:1801-13. doi: $10.2337 / \mathrm{db} 11-0832$

114. Sun K, Kusminski CM, Luby-Phelps K, Spurgin SB, An YA, Wang QA, et al. Brown adipose tissue derived VEGF-A modulates cold tolerance and energy expenditure. Mol Metab (2014) 3:474-83. doi:10.1016/j.molmet.2014.03.010

115. Nguyen KD, Qiu Y, Cui X, Goh YP, Mwangi J, David T, et al. Alternatively activated macrophages produce catecholamines to sustain adaptive thermogenesis. Nature (2012) 480:104-8. doi:10.1038/nature10653

116. Bassaganya-Riera J, Misyak S, Guri AJ, Hontecillas R. PPAR gamma is highly expressed in $\mathrm{F} 4 / 80$ (hi) adipose tissue macrophages and dampens adipose-tissue inflammation. Cell Immunol (2009) 258:138-46. doi:10.1016/j.cellimm.2009. 04.003
117. Stienstra R, Duval C, Keshtkar S, van der Laak J, Kersten S, Müller M. Peroxisome proliferator-activated receptor gamma activation promotes infiltration of alternatively activated macrophages into adipose tissue. J Biol Chem (2008) 283:22620-7. doi:10.1074/jbc.M710314200

118. Odegaard JI, Ricardo-gonzalez RR, Goforth MH, Christine R, Subramanian V, Mukundan L, et al. Macrophage-specific PPARgamma controls alternative activation and improves insulin resistance. Nature (2008) 447:1116-20. doi:10.1038/nature05894

119. Bouhlel MA, Derudas B, Rigamonti E, Dièvart R, Brozek J, Haulon S, et al. PPARgamma activation primes human monocytes into alternative M2 macrophages with anti-inflammatory properties. Cell Metab (2007) 6:137-43. doi:10.1016/j.cmet.2007.06.010

120. Guri AJ, Hontecillas R, Bassaganya-Riera J. Abscisic acid synergizes with rosiglitazone to improve glucose tolerance, down-modulate macrophage accumulation in adipose tissue: possible action of the cAMP/PKA/PPAR $\gamma$ axis. Clin Nutr (2011) 29:646-53. doi:10.1016/i.clnu.2010.02.003

121. Satoh T, Kidoya H, Naito H, Yamamoto M, Takemura N, Nakagawa K, et al. Critical role of Trib1 in differentiation of tissue-resident M2-like macrophages. Nature (2013) 495:524-8. doi:10.1038/nature11930

122. Akira S, Misawa T, Satoh T, Saitoh T. Macrophages control innate inflammation. Diabetes Obes Metab (2013) 15(Suppl 3):10-8. doi:10.1111/dom.12151

123. Sica A, Invernizzi P, Mantovani A. Macrophage plasticity and polarization in liver homeostasis and pathology. Hepatology (2014) 59:2034-42. doi:10.1002/ hep. 26754

124. Balmer ML, Slack E, de Gottardi A, Lawson MAE, Hapfelmeier S, Miele $\mathrm{L}$, et al. The liver may act as a firewall mediating mutualism between the host and its gut commensal microbiota. Sci Transl Med (2014) 6:237ra66. doi:10.1126/scitranslmed.3008618

125. Dambach DM, Watson LM, Gray KR, Durham SK, Laskin DL. Role of CCR2 in macrophage migration into the liver during acetaminophen-induced hepatotoxicity in the mouse. Hepatology (2002) 35:1093-103. doi:10.1053/jhep.2002. 33162

126. Zigmond E, Samia-Grinberg S, Pasmanik-Chor M, Brazowski E, Shibolet O, Halpern Z, et al. Infiltrating monocyte-derived macrophages and resident Kupffer cells display different ontogeny and functions in acute liver injury. J Immunol (2014) 193:344-53. doi:10.4049/jimmunol.1400574

127. Holt AP, Haughton EL, Lalor PF, Filer A, Buckley CD, Adams DH. Liver myofibroblasts regulate infiltration and positioning of lymphocytes in human liver. Gastroenterology (2009) 136:705-14. doi:10.1053/j.gastro.2008.10.020

128. You Q, Holt M, Yin H, Li G, Hu C-J, Ju C. Role of hepatic resident and infiltrating macrophages in liver repair after acute injury. Biochem Pharmacol (2013) 86:836-43. doi:10.1016/j.bcp.2013.07.006

129. Tarantino G, Saldalamacchia G, Conca P, Arena A. Non-alcoholic fatty liver disease: further expression of the metabolic syndrome. J Gastroenterol Hepatol $l$ (2007) 22:293-303. doi:10.1111/j.1440-1746.2007.04824.x

130. Loomba R, Sanyal AJ. The global NAFLD epidemic. Nat Rev Gastroenterol Hepatol (2013) 10:686-90. doi:10.1038/nrgastro.2013.171

131. Michelotti GA, Machado MV, Diehl AM. NAFLD, NASH and liver cancer. Nat Rev Gastroenterol Hepatol (2013) 10:656-65. doi:10.1038/nrgastro.2013.183

132. Sun B, Karin M. Obesity, inflammation, and liver cancer. J Hepatol (2014) 56:704-13. doi:10.1016/j.jhep.2011.09.020

133. Endo M, Masaki T, Seike M, Yoshimatsu H. TNF-a induces hepatic steatosis in mice by enhancing gene expression of sterol regulatory element binding protein-1c. Exp Biol Med (2007) 232:614-21.

134. Pandey AK, Munjal N, Datta M. Gene expression profiling and network analysis reveals lipid and steroid metabolism to be the most favored by TNFalpha in HepG2 cells. PLoS One (2010) 5:e9063. doi:10.1371/journal.pone. 0009063

135. Tosello-Trampont A-C, Landes SG, Nguyen V, Novobrantseva TI, Hahn YS. Kupffer cells trigger nonalcoholic steatohepatitis development in diet-induced mouse model through tumor necrosis factor- $\alpha$ production. J Biol Chem (2012) 287:40161-72. doi:10.1074/jbc.M112.417014

136. Musso G, Gambino R, Cassader M. Cholesterol metabolism and the pathogenesis of non-alcoholic steatohepatitis. Prog Lipid Res (2013) 52:175-91. doi:10.1016/j.plipres.2012.11.002

137. Jeon T-I, Osborne TF. SREBPs: metabolic integrators in physiology and metabolism. Trends Endocrinol Metab (2012) 23:65-72. doi:10.1016/j.tem.2011.10. 004 
138. Shimomura I, Matsuda M, Hammer RE, Bashmakov Y, Brown MS, Goldstein JL. Decreased IRS-2 and increased SREBP-1c lead to mixed insulin resistance and sensitivity in livers of lipodystrophic and ob/ob mice. Mol Cell (2000) 6:77-86. doi:10.1016/S1097-2765(00)00009-5

139. Moon Y-A, Liang G, Xie X, Frank-Kamenetsky M, Fitzgerald K, Koteliansky V, et al. The Scap/SREBP pathway is essential for developing diabetic fatty liver and carbohydrate-induced hypertriglyceridemia in animals. Cell Metab (2012) 15:240-6. doi:10.1016/j.cmet.2011.12.017

140. Miele L, Valenza V, La Torre G, Montalto M, Cammarota G, Ricci R, et al. Increased intestinal permeability and tight junction alterations in nonalcoholic fatty liver disease. Hepatology (2009) 49:1877-87. doi:10.1002/hep.22848

141. Thuy S, Ladurner R, Volynets V, Wagner S, Strahl S, Königsrainer A, et al. Nonalcoholic fatty liver disease in humans is associated with increased plasma endotoxin and plasminogen activator inhibitor 1 concentrations and with fructose intake. J Nutr (2008) 138:1452-5.

142. Suganami T, Tanimoto-Koyama K, Nishida J, Itoh M, Yuan X, Mizuarai S, et al. Role of the toll-like receptor $4 / \mathrm{NF}-\mathrm{kappaB}$ pathway in saturated fatty acid-induced inflammatory changes in the interaction between adipocytes and macrophages. Arterioscler Thromb Vasc Biol. (2007) 27:84-91. doi:10.1161/01. ATV.0000251608.09329.9a

143. Yu M, Wang H, Ding A, Golenbock DT, Latz E, Czura CJ, et al. HMGB1 signals through toll-like receptor (TLR) 4 and TLR2. Shock (2006) 26:174-9. doi:10.1097/01.shk.0000225404.51320.82

144. Aron-Wisnewsky J, Gaborit B, Dutour A, Clement K. Gut microbiota and non-alcoholic fatty liver disease: new insights. Clin Microbiol Infect (2013) 19:338-48. doi:10.1111/1469-0691.12140

145. Soares J-B, Pimentel-Nunes P, Roncon-Albuquerque R, Leite-Moreira A. The role of lipopolysaccharide/toll-like receptor 4 signaling in chronic liver diseases. Hepatol Int (2010) 4:659-72. doi:10.1007/s12072-010-9219-x

146. Imajo K, Fujita K, Yoneda M, Nozaki Y, Ogawa Y, Shinohara Y, et al. Hyperresponsivity to low-dose endotoxin during progression to nonalcoholic steatohepatitis is regulated by leptin-mediated signaling. Cell Metab (2012) 16:44-54. doi:10.1016/j.cmet.2012.05.012

147. Miura K, Kodama Y, Inokuchi S, Schnabl B, Aoyama T, Ohnishi H, et al. Toll-like receptor 9 promotes steatohepatitis by induction of interleukin-1beta in mice. Gastroenterology (2010) 139:323.e-34.e. doi:10.1053/j.gastro.2010.03.052

148. Pellicoro A, Ramachandran P, Iredale JP, Fallowfield JA. Liver fibrosis and repair: immune regulation of wound healing in a solid organ. Nat Rev Immunol (2014) 14:181-94. doi:10.1038/nri3623
149. Brancato SK, Albina JE. Wound macrophages as key regulators of repair: origin, phenotype, and function. Am J Pathol (2011) 178:19-25. doi:10.1016/j.ajpath. 2010.08.003

150. Dooley S, ten Dijke P. TGF- $\beta$ in progression of liver disease. Cell Tissue Res (2012) 347:245-56. doi:10.1007/s00441-011-1246-y

151. Pesce JT, Ramalingam TR, Mentink-Kane MM, Wilson MS, El Kasmi KC, Smith AM, et al. Arginase-1-expressing macrophages suppress Th2 cytokinedriven inflammation and fibrosis. PLoS Pathog (2009) 5:e1000371. doi:10. 1371/journal.ppat.1000371

152. Ramachandran P, Pellicoro A, Vernon MA, Boulter L, Aucott RL, Ali A, et al. Differential Ly-6C expression identifies the recruited macrophage phenotype, which orchestrates the regression of murine liver fibrosis. Proc Natl Acad Sci U S A. (2012) 109:E3186-95. doi:10.1073/pnas.1119964109

153. Wan J, Benkdane M, Teixeira-Clerc F, Bonnafous S, Louvet A, Lafdil F, et al. M2 Kupffer cells promote M1 Kupffer cell apoptosis: a protective mechanism against alcoholic and nonalcoholic fatty liver disease. Hepatology (2014) 59:130-42. doi:10.1002/hep.26607

154. Wan J, Benkdane M, Alons E, Lotersztajn S, Pavoine C. M2 Kupffer cells promote hepatocyte senescence: an IL-6-dependent protective mechanism against alcoholic liver disease. Am J Pathol (2014) 184:1763-72. doi:10.1016/j.ajpath. 2014.02.014

Conflict of Interest Statement: The authors declare that the research was conducted in the absence of any commercial or financial relationships that could be construed as a potential conflict of interest.

Received: 12 September 2014; accepted: 17 December 2014; published online: 22 January 2015.

Citation: Dey A, Allen J and Hankey-Giblin PA (2015) Ontogeny and polarization of macrophages in inflammation: blood monocytes versus tissue macrophages. Front. Immunol. 5:683. doi: 10.3389/fimmu.2014.00683

This article was submitted to Molecular Innate Immunity, a section of the journal Frontiers in Immunology.

Copyright (c) 2015 Dey, Allen and Hankey-Giblin. This is an open-access article distributed under the terms of the Creative Commons Attribution License (CC BY). The use, distribution or reproduction in other forums is permitted, provided the original author(s) or licensor are credited and that the original publication in this journal is cited, in accordance with accepted academic practice. No use, distribution or reproduction is permitted which does not comply with these terms. 